\title{
¿En qué medida la cláusula Nación más Favorecida (NMF) viola el consentimiento del Estado receptor de una inversión para someterse a arbitraje y por qué?*
}

Gabriela Rivadeneira Chacón ${ }^{* *}$

Recibido/Received: 01/08/2019

Aceptado/Accepted: 02/08/2019

Sumario: 1. Introducción. 2. La cláusula NMF en el Derecho Internacional de las Inversiones. 2.1 Definición, características y naturaleza de la cláusula NMF. 2.2 Objeto de la cláusula NMF. 2.3 Estructura de la cláusula NMF. 3. Interacción de la cláusula NMF y el consentimiento de un Estado para acudir a arbitraje. 4. Uso de la cláusula NMF para modificar total o parcialmente el mecanismo de solución de controversias inversionista-Estado. 4.1 Uso de la cláusula NMF para prescindir del requisito de litigio en cortes nacionales por un periodo de tiempo determinado. 4.2 Análisis sobre la posible vulneración del consentimiento del Estado sobre el requisito de completar un periodo de litigio en cortes locales. 4.3 Utilización de la cláusula NMF para que se lleve a cabo el arbitraje bajo un mecanismo de solución de controversias distinto al pactado en el TBI. 4.4 Análisis sobre la vulneración al consentimiento

* Este artículo es una adaptación del Trabajo de Titulación presentado para la obtención del título de Abogada en la Universidad San Francisco de Quito, el cual se encuentra disponible en: $<$ https://bit.ly/2ONoGi3>

** Asociada de Andrade Veloz Abogados, LL.B. por la Universidad San Francisco de Quito, Candidata a la Maestría en Litigio y Arbitraje Internacional por la Universidad San Francisco de Quito, Candidata a la Maestría en Fiscalidad Internacional por la Universidad Internacional de la Rioja. Correo electrónico: grivadeneira@andradeveloz.com

G. Rivadeneira Chacón, “¿En qué medida la cláusula Nación más Favorecida (NMF) viola el consentimiento del Estado receptor de una inversión para someterse a arbitraje y por qué?", Revista Ecuatoriana de Arbitraje, No. 10, 2019, pp. 291-356. 
del Estado en la modificación del mecanismo de solución de disputas. 5. Uso de la cláusula NMF para expandir la jurisdicción del tribunal arbitral en cuestiones sustantivas. 5.1 Utilización de la cláusula NMF para arbitrar cuestiones no contenidas en la cláusula de resolución de disputas. 5.2 La vulneración al consentimiento a arbitrar del Estado, mediante la aplicación de la cláusula NMF a cuestiones excluidas en el tratado base. 6. Conclusiones.

Resumen: La cláusula de nación más favorecida (en adelante, NMF, o cláusula NMF) contenida en un tratado bilateral de inversiones (en adelante, TBIs) impone a los Estados parte del tratado la obligación de garantizar a los inversionistas, de la nacionalidad de uno de estos Estados y a su inversión, un trato no menos favorable que el trato otorgado a un inversionista de la nacionalidad de un tercer Estado. No cabe duda de que la aplicación de la cláusula NMF permite que los inversionistas se beneficien del tratamiento más favorable otorgado por un tercer TBI. Sin embargo, la posibilidad de aplicar las cláusulas NMF a cuestiones procedimentales es todavía controversial.

En los últimos años, los inversionistas extranjeros han visto en la cláusula NMF una herramienta para alterar las disposiciones establecidas en las cláusulas de resolución de disputas deun TBI o, peor aún, un mecanismo para escoger elementos favorables y crear su propia cláusula de solución de controversias. En este trabajo de investigación se observará que la aplicación de la cláusula NMF no altera el consentimiento del Estado receptor de una inversión de someterse a arbitraje en todos los casos, sino que dicho consentimiento únicamente se ve menoscabado cuando se alteran las condiciones esenciales para que se lleve a cabo el arbitraje. De este modo, se corroborará que el hecho de no cumplir con un requisito sobre el tiempo de litigo ante cortes nacionales no afecta la voluntad del Estado de arbitrar. Por el contrario, se evidenciará que en los casos en los que se busca: (i) cambiar el mecanismo de resolución de controversias; 
(ii) arbitrar una protección no contenida en la cláusula de solución de controversias; o (iii) incorporar definiciones distintas a las contenidas en el tratado base, sí constituyen violaciones al consentimiento para arbitrar.

Palabras Clave: cláusula NMF, consentimiento, arbitraje, mecanismo de solución de controversias, tratados bilaterales de inversión, protecciones sustantivas.

\section{In which cases does the Most Favoured Nation (MFN) Clause violate the consent of the investment's host State to arbitrate and why?}

Aвstract: The most-favoured-nation clause (onwards, MFN, or MFN clause) included in Bilateral Investment Treaties (onwards, BITs)imposescontractingStates partiestheobligation to guarantee investors of the nationality of one of these States, and their investments, a treatment no less favourable than the treatment given to an investor from the nationality of a third State. There is no doubt that the application of the MFN clause allows investors to benefit from a more favourable treatment contained in a third BIT. However, the use of MFN clauses for procedural issues is controversial.

In recent years, foreign investors have seen in the MFN clause a tool to modify provisions established in the dispute resolution clauses of a BIT or worse, a mechanism to choose favourable elements and create their own dispute settlement clause. In this research paper, we will show that the application of the MFN clause does not alter the host State's consent to arbitrate in all cases, but that consent is only diminished when the essential conditions to arbitrate are changed through the application of the MFN clause. Thus, it will be demonstrated that the failure to meet the requirement of a litigation period before national courts does not affect the State's consent to 
arbitrate. On the other hand, we will evidence that in cases in which: (i) the dispute resolution mechanisms are sought to be changed; (ii) the scope of the dispute resolution clause is to be broadened to cover standards of protection not contained in the BIT; (iii) or the incorporation of definitions not contained in the basic treaty do constitute violations to the consent to arbitrate.

KeYwords: MFN clause, consent, arbitration, dispute resolution mechanism, BITs, substantive protections.

\section{INTRODUCCIÓN}

En materia de inversiones, las cláusulas NMF son incorporadas para que los inversionistas extranjeros puedan beneficiarse de todos los derechos y garantías sustantivos contenidos en los diversos TBIs que el Estado receptor ha celebrado con otros Estados. Generalmente, la mayoría de TBIs contienen una referencia al trato de nación más favorecida ${ }^{1}$.

En la actualidad, no cabe duda de que la cláusula NMF aplica a las protecciones sustantivas garantizadas en un $\mathrm{TBI}^{2}$. Sin embargo, los inversionistas no sólo han buscado beneficiarse de los estándares de protección sustantivos mediante la aplicación de la cláusula NMF, sino que también han buscado extender la cláusula NMF a cuestiones procedimentales, pretendiendo modificar las cláusulas de resolución de disputas que un Estado ha pactado en un TBI con otro Estado. Además, se han iniciado demandas en las que los inversionistas han seleccionado elementos más favorables de las cláusulas de resolución de disputas contenidas en terceros tratados. De esta manera, se

1. Véase, United Nations Conference on Trade and Development, Most-favored Nation Treatment: UNCTAD Series on Issues in International Investment Agreements II, Nueva York y Ginebra, 2010, p. 13.

2. D. CARON \& E. ShirLow, "Most Favoured Nation Treatment - Substantive Protection in Investment Law", King's College London Law School, Research paper No. 2015-23, <https://ssrn.com/abstract $=2590557>(08 / 03 / 2018)$. 
abre la posibilidad de que mediante la aplicación de la cláusula NMF, los inversionistas puedan construir sus propias cláusulas arbitrales, obligando al Estado a someterse a un arbitraje bajo condiciones que no pactó y que nunca consintió.

Existe un gran debate acerca de la posibilidad de que la cláusula NMF se extienda a temas procedimentales, específicamente, a la cláusula de resolución de disputas y sobre las consecuencias que esta aplicación podría generar³.

La jurisprudencia en materia de inversiones ha sido contradictoria respecto a los usos que los inversionistas le han pretendido dar a la cláusula NMF. Así, en los casos en los que se ha solicitado la aplicación de la cláusula NMF para prescindir del requisito de litigio en cortes locales, en laudos como Wintershall ${ }^{4}$, ICS $^{5}$, Daimler ${ }^{6}$, Impregilo ${ }^{7}$ y $\mathrm{Kilic}^{8}$, los tribunales no permitieron que se aplique la cláusula NMF para que el inversionista pueda acudir a arbitraje internacional directamente. Por otra parte, tribunales de los casos Maffezini ${ }^{9}$, Gas Natural ${ }^{10}$, National Grid ${ }^{11}$, Hochtiefi2, Camuzzi ${ }^{13}, A W G^{14}$,

3. J. Waincymer, "Procedure and Evidence in International Arbitration", The Procedural Framework for International Arbitration, Kluwer Law International, 2002, pp. 127-216.

4. Wintershall Aktiengesellschaft c. República Argentina, Caso CIADI No. ARB/ 04/14, Laudo, 08/12/2008.

5. ICS Inspection y Control Services Limites c. República Argentina, Caso Corte Permanente de Arbitraje No. 2010-9, Laudo sobre Jurisdicción, 10/02/2012.

6. Daimler Financial Services AG c. República Argentina, Caso CIADI No. ARB/05/1, Laudo, $22 / 08 / 2012$.

7. Impregilo S.p.A c. República Argentina, Caso CIADI No. ARB/07/17, Decisión del Comité Ad Hoc sobre la Solicitud de Anulación, 24/01/2014.

8. Kiliç Ǐnşaat Ĭthalat Ĭhracat Sanayi ve ticaret Anonim Şirketi c. Turkmenistán, Caso CIADI No. ARB/10/1, Laudo, 02/07/2013.

9. Emilio Agustín Maffezini v. Reino de España, Caso CIADI No. ARB/97/7, Decisión del Tribunal sobre excepciones a la Jurisdicción, 25/01/2000.

10. Gas Natural SDG S.A. c. República Argentina, Caso CIADI No. ARB/03/10, Decisión del Tribunal sobre Preguntas Preliminares sobre Jurisdicción, 17/06/2005.

11. National Grid PLC c. República Argentina, Caso CNUDMI, Decisión sobre Competencia, 20/06/2006.

12. Hochtief AG c. República Argentina, Caso CIADI No. ARB/07/31, Decisión sobre Jurisdicción, 24/10/2011.

13. Camuzzi Internacional S.A c. República Argentina, Caso CIADI No. ARB/03/2, Decisión sobre excepciones a la Jurisdicción, 11/05/2005.

14. AWG Group Ltd. c. República Argentina, Caso CIADI No. ARB/03/19, Decisión sobre Jurisdicción, 03/08/2006. 
Phillip Morris ${ }^{15}$, Suez ${ }^{16}$, Telefónica ${ }^{17}$ y Teinver $^{18}$, han permitido la aplicación de la cláusula NMF para que los inversionistas se beneficien de una cláusula de solución de disputas más favorable y no se vean obligados a litigar en cortes nacionales.

En los casos en los que los inversionistas han buscado cambiar las reglas del arbitraje, a través de la aplicación de la cláusula NMF, para que el arbitraje se lleve bajo un mecanismo distinto al pactado en el TBI, el único caso en el que se aceptó esta aplicación de la cláusula NMF fue el caso Venezuela U.S. c. Venezuela ${ }^{19}$, mientras que la extensión de la cláusula NMF fue negada en los casos Plama c. Bulgaria ${ }^{20}$, Wintershall c. Argentina ${ }^{21}$ y Garanti Koza c. Turkmenistán ${ }^{22}$.

Uno de los usos más controversiales de la cláusula NMF radica en intentar expandir la jurisdicción de los tribunales arbitrales poniendo a su conocimiento una demanda por una protección no contenida en la cláusula de resolución de disputas o una definición no incluida en el tratado en el que el inversionista basa su reclamación. Aquello ocurrió en los casos Salini c. Jordania ${ }^{23}$, Telenor c. Hungría ${ }^{24}$ Sanum c. Laos ${ }^{25}, H E H$ c.

15. Phillip Morris c. República Oriental del Uruguay, Caso CIADI No. ARB/10/7, Decisión sobre Jurisdicción, 02/07/2013.

16. Suez, Sociedad General de Aguas de Barcelona S.A. y Vivendi S.A. c. República Argentina, Caso CIADI No. ARB/03/19, Decisión sobre Anulación, 07/01/2015.

17. Telefónica S.A. c. República Argentina, Caso CIADI No. ARB/03/20, Decisión del Tribunal sobre las Objeciones a Jurisdicción, 25/05/2006.

18. Teinver S.A., Transportes de Cercanías S.A. y Autobuses Urbanos del Sur S.A. c. República Argentina, Caso CIADI No. ARB/09/01, Decisión sobre Jurisdicción, 21/12/2012.

19. Venezuela US, S.R.L. c. República Bolivariana de Venezuela, Caso CPA No. 2013-34, Laudo Interino sobre Jurisdicción, 26/07/2016.

20. Plama Consortium Limited c. República de Bulgaria, Caso CIADI No. ARB/03/24, Decisión de Jurisdicción, 08/02/2005.

21. Wintershall Aktiengesellschaft c. Argentina, N. 4.

22. Garanti Koza LLP c. Turkmenistán, Caso CIADI No. ARB/11/20, Decisión sobre la Objeción a Jurisdicción por falta de consentimiento, 03/07/2013.

23. Salini Costruttori S.p.A. y Italstrade S.p.A. c. Reino de Jordania, Caso CIADI No. ARB/02/13, Decisión de Jurisdicción, 09/11/2004.

24. Telenor Mobile Communications A.S. c. República de Hungría, Caso CIADI No. ARB/04/15, Laudo, 13/09/2010.

25. Sanum Investments Limited c. República Popular Democrática de Laos, Corte Permanente de Arbitraje Caso No. 2013-13, Decisión sobre Jurisdicción, 13/12/2013. 
Egipto $^{26}$, Austrian Airlines c. Eslovaquia ${ }^{27}$, Servier c. Polonia ${ }^{28}$, Berschader c. Rusia ${ }^{29}$, Renta 4 c. Rusia $a^{30}$, Tza Yap Schum c. Perúu, RosInvest c. Rusia ${ }^{32}$, Beijing Urban Constructions c. Yemen ${ }^{33}$. De los casos mencionados, exclusivamente en el caso Rosinvest c. Rusia se permitió el uso de la cláusula NMF y en los casos Metal-Tech c. Uzbekistán ${ }^{34}$, Vanessa Ventures c. Venezuela ${ }^{35}$, Rafat Ali Rizvi c. Indonesia ${ }^{36}$, se decidió que no se podía aplicar una definición de inversión de otro tratado a través de la cláusula NMF.

Actualmente, los tribunales arbitrales y los Estados receptores de inversiones ya no solo deben enfrentarse a la posibilidad de que la cláusula NMF extienda sus efectos a temas de jurisdicción, sino a que los inversionistas traten de crear sus propias cláusulas arbitrales extrayendo elementos de las cláusulas de resolución de disputas de otros tratados. Tales elementos pueden consistir en prescindir del período de tiempo de litigio en cortes nacionales, incluir dentro del arbitraje alguna protección que no estaba prevista en la cláusula de resolución de disputas o a su vez, invocar un método distinto de resolución de disputas distinto al previsto en el $\mathrm{TBI}^{37}$.

26. H\&H Enterprises Investments, Inc c. República Árabe de Egipto, Caso CIADI No. ARB/09/15, Laudo, 06/05/2014.

27. Austrian Airlines c. República de Eslovaquia, Arbitraje Ad-hoc bajo reglas CNUDMI, Laudo, 09/10/2009.

28. Les Laboratoires Servier, S.A.S. Biofarma, S.A.S., Arts y Techniques du Progres S.A.S. c. República de Polonia, Corte Permanente de Arbitraje, Laudo, 14/02/2012.

29. Vladimir Berschader y Moïse Berschader c. Federación Rusa, Caso No. 080/2004, Instituto de Arbitraje de la Cámara de Comercio de Estocolmo Caso No. 080/2004, Laudo, 21/04/2006.

30. Renta 4 S.V.S.A., et al c. Federación Rusa, Instituto de Arbitraje de la Cámara de Comercio de Estocolmo Caso No. 024/2007, Laudo sobre Objeciones Preliminares, 20/03/2009.

31. Tza Yap Schum c. República del Perú, Caso CIADI No. ARB/07/6, Decisión sobre Jurisdicción y Competencia, 19/06/2009.

32. RosInvest Co. UK Ltda. c. Federación Rusa, Instituto de Arbitraje de la Cámara de Comercio de Estocolmo Caso No. V079/2005, Laudo sobre Jurisdicción, 01/10/2007.

33. Beijing Urban Construction Group. c. República de Yemen, Caso CIADI No. ARB14/30, Decisión de Jurisdicción, 31/05/2017.

34. Metal-Tech Ltda. c. República de Uzbekistán, Caso CIADI No. ARB/10/3, Laudo, 04/10/2013.

35. Vanessa Ventures Ltda. c. República Bolivariana de Venezuela, Caso CIADI No. ARB (AF)/04/6, Laudo, 16/01/2013.

36. Rafat Ali Rizvi c. República de Indonesia, Caso CIADI No. ARB/11/13, Laudo de Jurisdicción, $16 / 07 / 2013$.

37. Véase, United Nations Conference on Trade and Development, N. 1, p. 83. 


\section{La cláusula NMF en el Derecho Internacional de LAS INVERSIONES}

A lo largo de esta sección se analizará la cláusula NMF en el contexto del Derecho Internacional de las Inversiones. Para ello, en primer lugar, se definirá a la cláusula NMF [2.1]. Posteriormente, se explicará el objeto [2.2] y la estructura de la cláusula [2.3].

\subsection{Definición, características y naturaleza de la cláusula NMF}

La cláusula NMF ha sido definida por la Comisión de Derecho Internacional como: “[...] una disposición de un tratado según la cual un Estado se obliga con otro Estado a otorgar el trato de nación más favorecida en una esfera de relaciones acordada" ${ }^{38}$. La cláusula NMF es una obligación que debe estar contenida en un tratado específico, a este tratado se lo conoce como "tratado base" ${ }^{\prime 39}$.

La cláusula NMF es considerada un estándar relativo, debido a que requiere de una prueba comparativa para su aplicación. En este sentido, la Conferencia de las Naciones Unidas sobre Comercio y Desarrollo (en adelante, CNUCYD) ha establecido:

El trato NMF [...] requiere una comparación, así como la búsqueda de un trato más favorable otorgado a los inversionistas de una nacionalidad determinada en contraposición a los inversionistas cubiertos por el tratado base. Por esa razón, la norma carece de un contenido definido a priori y no evitaría ni atacaría actos arbitrarios en los que todos los inversionistas extranjeros recibieran un trato igualmente malo (sin perjuicio de que se puedan encontrar otras violaciones). Cualquier evaluación de una supuesta violación llama no solo para encontrar una diferencia objetiva en el trato entre dos inversionistas extranjeros, pero también

38. Traducción libre. Yearbook of the International Law Comission, Report of the International Law Comission on its thirtieth session, Vol. II, Part Two, 1978, Art. 4.

39. Véase, United Nations Conference on Trade and Development, N. 1, p. 22. 
para una desventaja competitiva directamente derivada de esta diferencia en el tratamiento $[\ldots]^{40}$.

Cabe mencionar que el estándar establecido por la cláusula NMF se caracteriza por estar regido por el principio ejusdem generis $^{41}$. Esto significa que se puede aplicar la cláusula NMF a cuestiones que son parte de la misma materia o a la misma categoría de sujetos ${ }^{42}$.

El uso de la cláusula NMF de requiere una base legítima de comparación ${ }^{43}$ y se refiere a situaciones en las que se discrimina a un inversionista en razón de su nacionalidad. Para establecer que ha existido una violación a la obligación impuesta por una cláusula NMF se debe acreditar que la diferencia en el trato al inversionista se debe a la nacionalidad del inversionista extranjero ${ }^{44}$.

\subsection{Objeto de la cláusula NMF}

La cláusula NMF se incluye frecuentemente en los TBIs celebrados entre Estados y permite que los nacionales de uno de los Estados contratantes puedan beneficiarse del trato favorable que uno de los Estados parte otorga a nacionales de un tercer Estado ${ }^{45}$. Las cláusulas NMF tienen como propósito garantizar la igualdad de condiciones entre inversionistas extranjeros de diferentes nacionalidades que buscan constituir una inversión o que operan una inversión en el Estado receptor $^{46}$. La CNUCYD ha determinado:

\footnotetext{
40. Traducción libre. Ídem, p. 22.

41. El principio Ejusdem Generis limita la aplicación de una cláusula NMF a los asuntos de la misma materia que se encuentre en el tratado base.

42. Véase, United Nations Conference on Trade and Development, N. 1, p. 25.

43. La CNUCYD ha establecido que se debe aplicar la cláusula NMF en situaciones objetivamente similares, lo cual no significa que todos los inversionistas deban recibir un trato igualitario en todas las circunstancias. Se justifica un trato diferenciado por parte del Estado receptor hacia los inversionistas cuando su situación no es la misma, no operan en el mismo sector económico o no tienen la misma estructura corporativa.

44. Véase, United Nations Conference on Trade and Development, N. 1, p. 14.

45. M. SoRnARAJAH, "The International Law on Foreing Investement", Bilateral Investment Treaties, Cambridge University Press, 2010, pp. 201-205.

46. Véase, United Nations Conference on Trade and Development, N. 1, p. 14.
} 
[...] la cláusula de NMF cumple la función de garantizar la igualdad de trato y condiciones entre los inversionistas extranjeros, ya sea que intente liberalizar las condiciones de entrada y operación de inversionista extranjeros y/u ofrezca protección a los inversionistas y sus inversiones sin ningún compromiso de que estas condiciones sean más fáciles, más liberales o menos restrictivas ${ }^{47}$.

Dentro del ámbito del Derecho Internacional de las Inversiones, las cláusulas NMF se caracterizan por ser recíprocas e incondicionales ${ }^{48}$. De la misma manera, la aplicación de las cláusulas NMF rompe la lógica del Derecho Internacional que en principio, permite a los Estados otorgar un trato diferente a los nacionales de otro Estado ${ }^{49}$. Además, la determinación de una violación al estándar NMF requiere que exista un tratamiento ${ }^{50}$ menos favorable hacia el inversionista, en el sentido de que un tratamiento diferente no siempre significa un trato menos favorable y un tratamiento menos favorable se basa en premisas objetivas y, no en percepciones ${ }^{51}$.

Finalmente, la cláusula NMF debe ser interpretada de acuerdo a las reglas generales de interpretación de los tratados, específicamente bajo las reglas previstas en el artículo 31 de la Convención de Viena sobre el Derecho de los Tratados ${ }^{52}$.

47. Traducción libre. Ibídem, p. 27.

48. P. AcCONCI, "Most Favoured Nation Treatment and the International Law on Foreign Investment", en P. Muchlinkski et al. (Eds.), The Oxford Handbook of International Investment Law, Oxford University Press, 2005.

49. S. Schill, "The Multilateralization of International Investment Law", Multilateralization through Most-Favoured-Nation Treatment, Cambridge University Press, 2009, p. 121.

50. Traducción libre. United Nations Conference on Trade and Development, N. 1, p. 28.

"El tratamiento del Estado se materializa mediante "[...] el inversionista extranjero cubierto por una cláusula de trato NMF tiene derecho a recibir cualquier trato más favorable que reciba un tercer inversionista extranjero en cualquiera de estas áreas de las leyes y reglamentos del Estado anfitrión, ya sea de aplicación general o específico de inversión extranjera".

51. Véase, United Nations Conference on Trade and Development, N. 1, p. 29.

52. Convención de Viena sobre el Derecho de los Tratados (1969), Art. 31.

1. Un tratado deberá interpretarse de buena fe conforme al sentido corriente que haya de atribuirse a los términos del tratado en el contexto de estos y teniendo en cuenta su objeto y fin.

2. Para los efectos de la interpretación de un tratado. el contexto comprenderá, además del texto, incluidos su preámbulo y anexos:

a) todo acuerdo que se refiera al tratado y haya sido concertado entre todas las partes con motivo de la celebración del tratado: 


\subsection{Estructura de la cláusula NMF}

Según Schill, para que una cláusula NMF opere es necesario que exista una relación entre por lo menos tres Estados. El Estado A (Estado receptor de la inversión) que se obliga con el Estado B (Estado beneficiario) a extender los derechos y beneficios al Estado $C^{53}$. Al respecto, el tribunal del caso Renta 4 c. Federación Rusa señaló:

[...] El tratado que contiene la promesa de NMF se conoce convencionalmente como el "tratado base". El tratado invocado como prueba de un trato más favorable puede denominarse "tratado de comparación". La parte que hace valer un derecho a través de la cláusula NMF no es parte del tratado de comparación y, por lo tanto, no está en posición de presentar ninguna reclamación sobre este. El reclamo solo puede surgir bajo el tratado base $\mathrm{e}^{54}$.

La relación entre el Estado otorgante y el beneficiario no se ve afectada por la relación que el Estado otorgante pueda mantener con cualquier otro Estado. Por el contrario, el contenido del tratado celebrado con un tercer Estado es el medio por el cual opera la cláusula $\mathrm{NMF}^{55}$.

\section{INTERACCIÓN DE LA CLÁUSULA NMF Y EL CONSENTIMIENTO DEl Estado Para ACUDir a ARbitraje}

Para que un tribunal arbitral tenga jurisdicción es necesario el consentimiento de someterse a arbitraje, tanto del

b) todo instrumento formulado por una o más partes con motivo de la celebración del tratado y aceptado por las demás como instrumento referente al tratado;

3. Juntamente con el contexto, habrá de tenerse en cuenta:

a) todo acuerdo ulterior entre las partes acerca de la interpretación del tratado o de la aplicación de sus disposiciones;

b) toda práctica ulteriormente seguida en la aplicación del tratado por la cual conste el acuerdo de las partes acerca de la interpretación del tratado;

c) toda forma pertinente de derecho internacional aplicable en las relaciones entre las partes.

4. Se dará a un término un sentido especial si consta que tal fue la intención de las partes.

53. S. SChILl, N. 49, p. 126.

54. Traducción libre. Renta 4 S.V.S.A., et al. c. Federación Rusa, N. 30, párrafo 77.

55. S. SCHILl, N. 49, p. 127. 
Estado receptor de la inversión, como del inversionista ${ }^{56}$. Todo proceso arbitral nace del consentimiento de las dos partes para someter sus disputas a sede arbitral ${ }^{57}$. Por lo tanto, sin consentimiento no puede haber arbitraje ${ }^{58}$.

El Estado receptor de una inversión puede manifestar su consentimiento para someterse a arbitraje de tres maneras: (i) mediante una cláusula arbitral incluida en un contrato que se haya celebrado directamente entre el Estado y el inversionista; (ii) una cláusula de resolución de disputas contenida en un TBI; y, (iii) una oferta de arbitraje mediante una ley nacional ${ }^{59}$.

El primer mecanismo para que exista consentimiento para someter una disputa a arbitraje internacional consiste en pactar una cláusula arbitral o una cláusula compromisoria en un contrato de inversión que haya sido celebrado entre el Estado y el inversionista ${ }^{60}$. Los contratos de inversión son acuerdos celebrados entre el Estado y un privado, en los cuales se crea una organización para controlar una actividad económica ${ }^{61}$. Es recomendable que las partes limiten la cláusula arbitral a temas que realmente desean arbitrar para evitar extensiones no deseadas sobre la materia arbitrable ${ }^{62}$.

Por otra parte, el Estado manifiesta su voluntad de someterse a arbitraje mediante una ley nacional, aquella ley opera como una oferta abierta de arbitraje. Esta oferta requiere

56. A. GALINDO, "El consentimiento en el arbitraje internacional en materia de Inversiones", Iuris Dicto, Vol. 14, 2012, p. 42.

57. A. RedFern \& M. Hunter, "The Agreement to Arbitrate", Redfern and Hunter on International Arbitration, Oxford University Press, 2015, pp. 5-3.

58. G. Born, "International Arbitration: cases and materials", International Arbitration Agreements: Basic Issues, Kluwer Law International, 2015, p. 159.

59. Véase, C. Schreuer, "Consent to Arbitration", The Oxford Handbook of International Investment Law, Oxford University Press, $\square$ https://bit.ly/31vUwkG $\square$ (15/03/2018).

60. Ibídem.

61. Y. PÉrez PACHECo, "Consentimiento estatal al arbitraje del CIADI”, Lecciones y Ensayos, No. 91, 2013, p. 34, <https://bit.ly/2YZ9DkZ> (08/03/2018).

62. Ídem, p. 36. 
la aceptación del inversionista ${ }^{63}$, sea por escrito o mediante la iniciación del proceso arbitral ${ }^{64}$.

El problema que puede generar esta forma de consentir a ventilar una disputa en arbitraje es que si el Estado realiza una oferta de arbitraje mediante una ley nacional, esta ley puede ser fácilmente derogada o enmendada por el Estado receptor de la inversión ${ }^{65}$.

La tercera manera de obtener el consentimiento de un Estado para someterse a arbitraje es a través de una cláusula de resolución de disputas que se incluya en un acuerdo recíproco de protección y promoción de inversiones ${ }^{66}$. Al igual que lo ocurre en las ofertas de arbitraje en leyes nacionales, el acuerdo de arbitraje se perfecciona con la aceptación de quien realiza la inversión ${ }^{67}$. En tal sentido, PÉREz PACHECo sostiene:

[...] el convenio arbitral es la base del arbitraje de inversión que como todo contrato se sustenta en el consentimiento, el cual en el caso de una oferta que ha sido otorgada por el Estado debe ser aceptada por el inversionista ${ }^{68}$.

Como ya se mencionó en secciones anteriores, los TBIs tienen la calidad de instrumentos de Derecho Internacional Público, por lo cual, deben interpretarse de acuerdo a las reglas de interpretación de la Convención de Viena sobre el Derecho de los Tratados. Así, el consentimiento el Estado de someterse a arbitraje puede depender de la interpretación que realice el tribunal arbitral sobre la existencia de una inversión, la nacionalidad del inversionista y las protecciones otorgadas en el tratado ${ }^{69}$.

63. J. O. Voss, The impact of Investment Treaties on Contracts between Host States and Foreign Investors, Martinus Nijhoff Publishers, 2010, p. 59.

64. Y. Pérez Pacheco, N. 61, p. 40.

65. J. O. Voss, N. 63, p. 59.

66. Ídem, p. 60.

67. Ídem, p. 62.

68. Y. Pérez Pacheco, N. 61, p. 34.

69. K. H. Böckstiegel, Commercial and Investment Arbitration: How different are they today?, Kluwer Law Arbitration, 2012, p. 583. 
Las opciones de elección de la institución administradora del arbitraje en un tratado bilateral de inversiones son amplias ${ }^{70}$. Existen tratados que se refieren únicamente a una institución arbitral, mientras que otros se refieren a varias instituciones arbitrales o a arbitrajes ad hoc ${ }^{71}$. Asimismo, existen TBIs que contienen cláusulas de resolución de disputas en las que se limita el arbitraje a temas específicos y otros que contienen una redacción amplia que permite que se someta a arbitraje cualquier disputa derivada del TBI. Por esta razón, se ha divido a los tratados bilaterales de inversiones en dos grandes grupos:

(i) Tratados que contienen una cláusula de resolución de disputas amplia, por lo general contienen frases como "cualquier" o "todas las disputas" relacionadas con la inversión ${ }^{72}$.

(ii) Tratados que garantizan el arbitraje internacional bajo ciertas condiciones, por ejemplo, existen TBIs que limitan el arbitraje a protecciones específicas o a requerimientos procedimentales $^{73}$.

El consentimiento para arbitrar, plasmado en un TBI es una obligación de los Estados suscriptores del tratado. En palabras de NolAn y SOURGENS:

[...] el consentimiento al arbitraje en un acuerdo de inversión bilateral típico constituye una obligación del Estado signatario para arbitrar si se perfecciona alguna vez o no. El hecho de que la obligación nunca pueda ser aplicada por un inversionista no cambia su naturaleza fundamental como un compromiso internacional jurídicamente vinculante de un estado incluido en un tratado aceptado por el inversionista ${ }^{74}$.

70. J. O. Voss, N. 63, p. 60.

71. Ídem, p. 62.

72. J. O. Voss, N. 63, p. 66.

73. Ídem, p. 67.

74. Traducción libre. M. D. Nolan \& F. G. Sourgens, "Limits of Consent- Arbitration without Privity and Beyond", Liber Amicorum Bernardo Cremades, Kluwer Law International, 2010, p. 585. 
Es necesario aclarar que en el presente trabajo de investigación se analizará únicamente el consentimiento del Estado para acudir a arbitraje otorgado sobre la base de un TBI con el propósito de determinar si dicho consentimiento es vulnerado por la aplicación de la cláusula NMF.

En el siguiente capítulo se expondrán casos en los que se ha solicitado la aplicación de la cláusula NMF para prescindir del requisito de litigar en cortes nacionales por un lapso de tiempo establecido en el TBI y casos en los que se ha buscado cambiar el mecanismo de solución de controversias incluido en el tratado. Por último, se analizará si dichas aplicaciones de la cláusula NMF configuran una violación al consentimiento receptor de una inversión de someterse a arbitraje.

\section{Uso de la ClÁUSUla NMF PARA MOdificar tOTAL O PARCIALMENTE EL MECANISMO DE SOLUCIÓN DE CONTROVERSIAS INVERSIONISTA-ESTADO}

Existen numerosos casos en los que inversionistas han buscado utilizar la cláusula NMF para neutralizar ciertos requisitosocondiciones establecidosenla cláusula deresolución de controversias del tratado base. Aquellos inversionistas han basado sus pretensiones en TBIs celebrados entre el Estado en el que realizaron su inversión con terceros Estados. Así, los inversionistas han alegado que la cláusula NMF les garantiza un trato no menos favorable que el otorgado a un inversionista de un tercer Estado y que, consecuentemente, la cláusula de resolución de disputas, al ser parte de las protecciones del tratado, debe ser parte del tratamiento otorgado por la cláusula NMF.

En esta sección se examinarán casos en los que los inversionistas han invocado la cláusula NMF buscando beneficiarse de condiciones más favorables contenidas en la cláusula de resolución de disputas de un tercer tratado para 
así evadir el requisito de someterse a cortes nacionales por un período de tiempo determinado [4.1], o para cambiar las reglas de procedimiento del arbitraje [4.3]. A su vez, se analizará, luego de cada sección, si la aplicación de la cláusula NMF para estos fines modifica el consentimiento del Estado para someterse a arbitraje o no [4.2], [4.4].

\subsection{Uso de la cláusula NMF para prescindir del requisito de litigio en cortes nacionales por un período de tiempo determinado}

En la actualidad, la generalidad de acuerdos recíprocos de protección de inversiones incluyen ciertas etapas que el inversionista debería seguir antes de presentar una demanda de arbitraje internacional en contra del Estado en el que se ha realizado la inversión. Cuando los inversionistas no han cumplido los pasos previos para el arbitraje, han optado por invocar la cláusula NMF para aplicar así, una cláusula de resolución de disputas de otro tratado que resulte más favorable. Aquello ha ocurrido en los casos que se mencionarán a continuación:

En el caso Maffezini c. España, el TBI España-Argentina exigía que se someta la controversia a las cortes locales del Estado receptor de la inversión por el trascurso de 18 meses. Con el objetivo de obviar este requisito, el inversionista pidió al tribunal arbitral que se aplique la cláusula NMF para aprovecharse de la cláusula de resolución de disputas del TBI España-Chile que permitía demandar en arbitraje directamente después de los 6 meses de negociaciones previas ${ }^{75}$. El tribunal concluyó:

[...] si un tratado con un tercero contiene disposiciones para la solución de controversias que sean más favorables para la protección de los derechos e intereses del inversionista

75. Emilio Agustín Maffezini c. España, N. 9, párrafo 39. 
que aquellos del tratado básico, tales disposiciones pueden extenderse al beneficiario de la cláusula de la nación más favorecida pues son plenamente compatibles con el principio ejusdem generis. Naturalmente que el tratado con el tercero tiene que referirse a la misma materia del tratado básico, sea ésta la protección de inversiones extranjeras o la promoción del comercio, puesto que las disposiciones sobre solución de controversias se aplicarán en el contexto de estas materias; de otro modo se incurriría en contravención de dicho principio. Esta aplicación de la cláusula de la nación más favorecida tiene, sin embargo, algunos límites derivados de consideraciones de política pública que se expondrán más adelante $[\ldots]^{76}$.

En el caso Phillip Morris c. Uruguay, el tribunal tuvo que decidir si el inversionista podía prescindir del requisito de litigar 18 meses en cortes uruguayas. El inversionista buscó aplicar la cláusula NMF para beneficiarse de la cláusula de resolución de disputas del TBI Uruguay-Canadá o del TBI Uruguay-Australia, las cuales no exigían que el inversionista acuda a cortes uruguayas ${ }^{77}$. El tribunal arbitral resolvió que la facultad de iniciar un arbitraje sin someter la disputa a cortes locales es más favorable para los inversionistas. Por lo tanto, el tribunal afirmó que el tratamiento garantizado por la cláusula NMF no se limitaba solo a protecciones sustantivas, sino también a la cláusula de resolución de disputas ${ }^{78}$. Según el tribunal, en ausencia de una redacción que demuestre lo contrario, la cláusula NMF debía extenderse a temas procedimentales ${ }^{79}$.

En el caso Siemens c. Argentina, el inversionista trataba de recurrir a la cláusula NMF para aplicar la cláusula de resolución de disputas del TBI Argentina-Chile para evadir el requisito de litigar 18 meses en cortes argentinas. El tribunal consideró que la reclamación de una ventaja por medio de

\footnotetext{
76. Ídem, párrafo 56 .

77. Phillip Morris c. Uruguay, N. 15, párrafo 47.

78. Ídem, párrafo 79.

79. Ídem, párrafo 80 .
} 
la cláusula NMF, no implicaba la aceptación de todos los términos del tratado, cuando esas ventajas no hubieren sido consideradas favorables. La aplicación o no de la cláusula NMF dependía de su redacción y de los demás términos del tratado. Pese a que el tribunal tomó en consideración lo manifestado en el caso Maffezini respecto de quien pretende beneficiarse de la cláusula NMF no podía inobservar consideraciones de orden público que hayan sido esenciales para la celebración del tratado; es decir, consideró que las alegaciones sobre orden público planteadas por Argentina no eran oportunas y permitió la aplicación de la cláusula NMF para beneficiar al inversionista con la cláusula de resolución de disputas de otro tratado ${ }^{80}$.

En el caso Suez Vivendi c. Argentina, el tribunal debía pronunciarse sobre si el requerimiento de acudir a cortes nacionales argentinas por 18 meses antes de acudir a arbitraje internacional podía ser obviado mediante la aplicación de la cláusula $\mathrm{NMF}$ de un tercer $\mathrm{TBI}^{\text {s1. }}$. Así, el tribunal determinó que cuando una cláusula NMF dentro de un TBI incluía la expresión "en todas las materias" e iba acompañado de excepciones específicas en las que no se incluía la cláusula de resolución de disputas, no cabía ninguna duda de que la solución de disputas estaba comprendida dentro de la cláusula NMF. Bajo estas razones, el tribunal resolvió que se podía iniciar un arbitraje internacional sin necesidad de recurrir a los tribunales locales argentinos ${ }^{82}$.

En el caso AWG c. Argentina, el inversionista demandó ante un tribunal arbitral sobre la base del TBI ArgentinaEspaña. Ese tratado exigía que se litiguen 18 meses ante jueces

80. Siemens A.G. c. República Argentina, Caso CIADI No. ARB/03/8, Decisión sobre Jurisdicción, 03/08/2004, párrafo 109.

81. El TBI España-Argentina imponía a los inversionistas el sometimiento a cortes nacionales argentinas por el período de 18 meses antes de acudir a arbitraje. El inversionista, por otra parte, sostenía que gracias a la aplicación de la cláusula NMF se le puede aplicar la cláusula de resolución de disputas del TBI Argentina-Alemania, que no exigía el requisito mencionado.

82. Suez et al. c. República Argentina, N. 16, párrafo 68. 
argentinos. Sin embargo, el inversionista invocó la cláusula NMF del TBI Argentina-Francia, que sólo requería 6 meses de negociaciones para que proceda el arbitraje internacional. El tribunal arbitral interpretó la cláusula NMF a la luz del artículo 31 de la Convención de Viena y concluyó que se podía invocar el trato más favorable contenido en la cláusula de resolución de disputas del TBI Argentina-Francia y con ello, iniciar un arbitraje internacional sin la necesidad de recurrir primero a los tribunales locales ${ }^{33}$.

De igual forma, en el caso Telefónica c. Argentina, de conformidad con el TBI Argentina-España antes de comenzar un arbitraje internacional, la disputa debía ser sometida ante cortes argentinas por 18 meses. El inversionista requirió que mediante la cláusula NMF se le aplique el TBI Argentina-Chile para no cumplir con el requisito mencionado ${ }^{84}$. El tribunal decidió que resulta más favorable para un inversionista no presentar la demanda ante cortes locales por el período de 18 meses, sino acudir directamente a arbitraje internacional, por lo tanto resolvió que la extensión de la cláusula NMF sí procedía ${ }^{85}$.

En el caso Teinver c. Argentina, el inversionista pretendía utilizar la cláusula NMF para que se aplique la cláusula de resolución de disputas del TBI Argentina-Estados Unidos y el TBI Argentina-Australia. A diferencia del TBI ArgentinaEspaña, que exigía que una vez que se haya originado la controversia se debían iniciar 6 meses de negociaciones directas y posteriormente, se tenía que litigar en cortes nacionales por otros 18 meses. El TBI invocado por el inversionista únicamente exigía que se intente resolver la disputa de manera amigable entre las partes antes de someterla a arbitraje internacional.

83. AWG Group Ltd. c. Argentina, N. 14, párrafo 68.

84. Argentina argumentó que tanto España como Argentina habían adoptado una práctica posterior respecto a la aplicación de la cláusula NMF para el requisito de los 18 meses y que, dicha práctica sería vinculante para ambos Estados.

85. Telefónica S.A. c. Argentina, N. 17, párrafo 103. 
El tribunal determinó que el inversionista podía invocar la cláusula NMF para acceder a las disposiciones de resolución de controversias establecida en el TBI Australia-Argentina. Según el tribunal, la fórmula "todas las materias" utilizada en la redacción de la cláusula NMF debía interpretarse de manera inclusiva. El tribunal determinó que la demandante si cumplió los requisitos para someter la disputa a arbitraje ${ }^{86}$.

En el caso Camuzzi c. Argentina, el inversionista solicitó la aplicación de la cláusula NMF para importar la cláusula de resolución de disputas del TBI Argentina-Estados Unidos que permitía que se acuda directamente a arbitraje internacional ${ }^{87}$. El tribunal señaló que Argentina no objetó la reclamación cuando culminó el proceso de negociaciones previas, por lo cual la vía del arbitraje se encontraba abierta y no era necesario pronunciarse sobre la cláusula $\mathrm{NMF}^{88}$.

En el caso Gas Natural c. Argentina, el tribunal consideró que la disposición referente al arbitraje internacional entre el inversionista y el Estado contenida en los tratados bilaterales de inversiones constituía un incentivo y un mecanismo de protección importante para los inversionistas extranjeros. Del mismo modo, sostuvo que el hecho de que solo se pueda tener acceso a ese arbitraje después de recurrir a los tribunales nacionales y una vez transcurrido un período de espera de 18 meses, implicaba un mecanismo de protección menos amplio que el acceso al arbitraje inmediatamente después de expirado el período de negociación. En consecuencia, el tribunal determinó que el inversionista tenía derecho a recurrir al mecanismo de solución de controversias previsto en el TBI entre Argentina y Estados Unidos invocando el Artículo IV (2) del tratado bilateral de inversiones entre España y Argentina ${ }^{89}$.

86. Teinver S.A. et al. c. Argentina, N. 18, párrafo 141.

87. Camuzzi Internacional S.A. c. Argentina, N. 13, párrafo 121.

88. Ídem, párrafo 122.

89. Gas Natural SDG S.A. c. Argentina, N. 10, párrafos 32-34. 
De igual manera, en el caso National Grid c. Argentina, el Tribunal observó que la cláusula NMF del TBI Argentina España no se refería expresamente a solución de controversias, ni a ninguna otra norma de trato prevista específicamente en el tratado. Por otra parte, el tribunal sostuvo que la solución de disputas de controversias no era una de las excepciones previstas a la aplicación de la cláusula. Desde el punto de vista de la interpretación, la mención específica de un asunto excluye a los restantes: expressio unius est exclusio alterius. El tribunal consideró queel "trato" previstoen la cláusula NMF del Tratado permitía a los inversionistas de Reino Unido en Argentina recurrir al arbitraje sin tener que comparecer previamente ante los tribunales argentinos, tal como lo autorizaba el TBI Estados Unidos-Argentina. Por lo tanto, el tribunal aceptó la aplicación de la cláusula NMFº.

En contraposición a los casos presentados anteriormente, existe jurisprudencia en la que se ha negado la aplicación de la cláusula NMF para cuestiones procedimentales. Un claro ejemplo de aquello es el caso Wintershall c. Argentina, en el cual, el tribunal observó que la cláusula NMF no incluía ninguna disposición que extendiera el alcance de su aplicación a la resolución de diferencias, ni tampoco contemplaba "todos los derechos" ni "todas las materias" comprendidas en el tratado. A más de esto, las demandantes no presentaron ninguna evidencia de la cual pudiera inferirse que la intención común de las partes era que la cláusula NMF se aplicara a la solución de controversias ${ }^{91}$. Finalmente, el tribunal decidió que la demandante no podía basarse en la cláusula NMF del Artículo 3 del TBI Argentina-Alemania, a fin de evitar el cumplimiento de los requisitos establecidos en el Artículo 10(2) del TBI ${ }^{92}$.

En el caso ICS c. Argentina, el inversionista buscaba que debido a la cláusula NMF se aplique a la controversia la cláusula

90. National Grid PLC c. Argentina, N. 11, párafos 81-84.

91. Wintershall Aktiengesellschaft c. Argentina, N. 4, párrafos158-162.

92. Ídem, párrafo 197. 
de resolución de disputas del TBI Argentina-Reino Unido que permitía el arbitraje internacional una vez que el período de negociación hubiere expirado93. El tribunal concluyó que los Estados parte del TBI condicionaron su consentimiento al arbitraje a un requisito que debía cumplirse y que en ese caso no se cumplió, por lo cual, el tribunal afirmó que no estaba facultado para ignorar los límites de jurisdicción impuestos por las partes. Así, el tribunal declinó su competencia y no analizó los alcances de la cláusula NMF; al considerar que la demandante incumplió los prerrequisitos contenidos en el TBI, sin que exista razón alguna para eximirla de su aplicación ${ }^{94}$.

En el caso Impregilo c. Argentina, la cláusula de resolución de disputas contenida en el artículo 8 del TBI Argentina-Italia requería que los inversionistas sometan las controversias ante tribunales argentinos durante 18 meses de manera previa al arbitraje internacional. Para poder someter la disputa directamente a arbitraje, Impregilo invocó la aplicación de la cláusula NMF para beneficiarse de la cláusula de resolución de disputas contenida en el TBI Argentina-Estados Unidos, para así poder someter a arbitraje las controversias luego de 6 meses de que esta se haya suscitado ${ }^{95}$. El tribunal determinó que la palabra "podrá" contenida en el artículo 8 del TBI señalaba que el inversionista no se encontraba obligado a someter la controversia a tribunales locales previo el arbitraje ${ }^{96}$. No obstante, el tribunal arbitral interpretó la intención de las partes contratantes en el TBI y determinó que el gobierno argentino debió haber deseado brindar primero una oportunidad a sus tribunales para resolver las controversias entre el Estado y el inversionista y que, esta oportunidad se vería truncada si el inversionista tuviera la elección de hacerlo o no ${ }^{97}$.

93. ICS Inspection and Control Services Limites c. Argentina, N. 5, párrafo 119.

94. Ídem, párrafo 250.

95. Impregilo S.p.A c. Argentina, N. 7, párrafo 74.

96. Ídem, párrafo 83.

97. Ídem, párrafo 88 . 
En el caso Kilic c. Turkmenistán, el inversionista quería beneficiarse de la cláusula de resolución de disputas del TBI Turkmenistán-Suiza ${ }^{98}$. El TBI Turkmenistán-Turquía, bajo el cual se presentaba la reclamación, enunciaba que el derecho del inversionista de presentar una demanda de arbitraje internacional estaba condicionado a que la disputa se someta primero a cortes locales y que esta no se haya resuelto en el período de un año. No obstante, el tribunal arbitral decidió que la cláusula NMF no aplicaba a las cláusulas de resolución de disputas de otros tratados y que consecuentemente, ni el tribunal ni el centro tenían jurisdicción ${ }^{99}$. Posteriormente, el tribunal realizó un análisis acerca de la futilidad del requisito de someter la disputa a cortes locales por un año y resolvió que solo en el caso en el que el requisito de someter la disputa a cortes nacionales resulte fútil, se podía prescindir del requisito impuesto en la cláusula de resolución de disputas del TBI ${ }^{100}$.

En el caso Hochtief c. Argentina, el inversionista debía someter la disputa a cortes locales argentinas por 18 meses antes de acudir a arbitraje y para no tener que verificar este requisito, mediante la cláusula NMF invocó la aplicación de la cláusula de resolución de disputas del TBI ArgentinaChile $^{101}$. El tribunal consideró que la cláusula NMF no permitía seleccionar componentes para fabricar un conjunto artificial de condiciones a las que ningún nacional del Estado tendría derecho ${ }^{102}$. Adicionalmente, el tribunal sostuvo que el inversionista debía basarse en la totalidad del régimen del TBI Argentina-Chile o del TBI Argentina-Alemania y no seleccionar sólo ciertos elementos de estos ${ }^{103}$.

98. Kiliç Ǐnşaat Ĭthalat Ĭhracat Sanayi ve ticaret Anonim Şirketi c. Turkmenistán, N. 8, párrafo 7.9.1. 99. Ibídem.

100. Ídem, párrafo 8.1.21.

101. Hochtief A G c. Argentina, N. 12, párrafo 62.

102. Ídem, párrafo 98.

103. Ídem, párrafo 97. El tribunal señaló que la frase "la administración, la utilización, el uso y el aprovechamiento de una inversión" incluye el derecho a recurrir a mecanismos de resolución de diferencias como un aspecto dentro de la administración de la inversión como un aspecto de la administración de la inversión. 
En el caso Daimler c. Argentina, el inversionista basó su reclamación en el TBI Argentina-Alemania que requería que previo acudir a arbitraje internacional se someta la disputa a cortes locales argentinas por el período de 18 meses. El tribunal decidió que cuando se trataba de un requisito de litigar en cortes nacionales no se podía establecer un criterio general, sino que se debía analizar las circunstancias de cada caso y la futilidad de la medida ${ }^{104}$. El tribunal señaló que el consentimiento es un principio que regula todo tipo de tratados celebrados entre Estados ${ }^{105}$. Según este tribunal, la jurisprudencia de tribunales que han conocido disputas entre el Estado y el inversionista había optado por interpretar los acuerdos recíprocos de protección de inversiones de conformidad con la Convención de Viena sobre el Derecho de los Tratados ${ }^{106}$. La Convención de Viena en el artículo 31 establece que se debía interpretar los tratados buena fe, de acuerdo a su objeto y propósito. Por lo cual, el tribunal se puso como labor determinar cuál era la voluntad de la República Federal de Alemania y la República de Argentina. El tribunal interpretó el artículo 10 del tratado y determinó que:

a. El proceso de solución de disputas era obligatorio y no opcional107.

b. La cláusula de resolución de disputas imponía ciertos pasos que el inversionista debía seguir necesariamente y no se trataba de una elección para el inversionista108.

c. Una disputa podía someterseanteun arbitrajeinternacional únicamente cuando:

a. Se hubiere sometido la disputa en cortes locales argentinas por 18 meses o;

104. Daimler c. Argentina, N. 6, párrafo 186.

105. Ídem, párrafo 168.

106. Ídem, párrafos 169-172.

107. Ídem, párrafo 181 .

108. Ídem, párrafo 182. 
b. Cuando las partes hubieren acordado prescindir de estos requisitos ${ }^{109}$.

Finalmente, el tribunal resolvió que el artículo 10(2) del TBI Alemania-Argentina buscaba brindarle a los tribunales domésticos la oportunidad de resolver la disputa de manera rápida, por lo tanto, los 18 meses de litigio ante cortes locales era una condición del Estado receptor de la inversión para someterse a arbitraje, por lo cual no podía alterarse el consentimiento a arbitrar por un mero asunto de jurisdicción o admisibilidad ${ }^{110}$.

Tal como se ha podido evidenciar, numerosos tribunales de arbitraje de inversiones se han enfrentado a demandas arbitrales en las que el inversionista incumplió las condiciones previas para el arbitraje, entre ellas, el litigio de 18 meses en cortes locales. Exclusivamente en los casos Wintershall, ICS, Daimler, Impregilo y Kilic se resolvió que era necesario que se cumpla el requisito de los 18 meses de litigio en cortes nacionales. En el caso ICS c. Argentina, se consideró que este requisito era parte de la oferta de arbitraje y que el inversionista, al aceptar la oferta, aceptaba todos los términos y condiciones contenidos en esta, de lo contrario, no existía acuerdo para arbitrar ${ }^{111}$. En Daimler c. Argentina se determinó que la cláusula de resolución de disputas establecía un proceso secuencial específico, cuyos pasos deben seguirse estrictamente "el artículo 10 no proporciona un menú a la carta de opciones de solución de controversias disponibles para los inversionistas" 112 .

La misma conclusión fue manifestada por los tribunales arbitrales de los casos Impregilo c. Argentina, en el cual, el tribunal sostuvo que el TBI contenía un requisito que debía

111. ICS Inspection y Control Services Limites c. Argentina, N. 5, párrafo 272.

112. Daimler c. Argentina, N. 6, párrafo 182. 
ser observado antes de que el tribunal pudiera declararse competente. Este criterio también fue compartido por el tribunal del caso Wintershall c. Argentina, que decidió que:

El inversionista puede elegir voluntariamente omitir el segundopaso[el requisitode 18 meses detribunalesnacionales] simplemente no está previsto por el TBI entre Argentina y Alemania, porque (Argentina) el "consentimiento" del Estado Anfitrión (oferta permanente) se basa en la premisa de que primero se somete a los tribunales de jurisdicción competente del Estado anfitrión toda la disputa para su resolución en los tribunales locales ${ }^{113}$.

A diferencia de los casos antedichos, los tribunales de los casos Maffezini, Gas Natural, National Grid, Hochtief, Camuzzi, AWG, Phillip Morris, Suez, Telefónica y Teinver han reconocido la importancia que tienen los requisitos previos al arbitraje en el consentimiento. Sin embargo, con la ayuda de la cláusula NMF los tribunales arbitrales han optado por dejar que se apliquen las disposiciones sobre solución de conflictos de otro tratado que no exigían los 18 meses en cortes nacionales.

\subsection{Análisis sobre la posible vulneración del consentimiento del Estado sobre el requisito de completar un periodo de litigio en cortes locales}

Existen ciertos acuerdos recíprocos de protección de inversiones que establecen ciertos pasos previos antes de someter la disputa a arbitraje internacional, estas cláusulas se han denominado como "cláusulas escalonadas". Un requisito que contienen generalmente las cláusulas de resolución de disputas de un TBI es el litigio en cortes locales por un lapso de tiempo específico ${ }^{114}$. Así, el requisito de esperar un período de tiempo o buscar solucionar la

113. Traducción libre. Wintershall Aktiengesellschaft c. Argentina, N. 4, párrafo 160.

114. C. SCHREUER, "Interaction of International Tribunals and Domestic Courts in Investment Law", en A. W. Rovine (Ed.), Contemporary Issues in International Arbitration and Mediation: The Fordham Papers, Vol. 4, Brill | Nijhoff, 2010, p. 74, $\square$ https://bit.ly/2H71Sna $\square(07 / 03 / 2018)$. 
controversia de forma amistosa se define como "cooling off period clauses" 115 .

Los requisitos previos al arbitraje, en principio, tienen como propósito evitar procesos legales que dilaten la disputa y que ocasionen que el conflicto escale. El objetivo de estas condiciones es que las partes resuelvan la controversia evitando la demora y los costos de procesos arbitrales reales ${ }^{116}$. Las cláusulas escalonadas traen como consecuencia que el inversionista pueda activar la vía arbitral solamente cuando haya concluido el tiempo en cortes nacionales o cuando se obtenga una decisión judicial que no ponga fin a la controversia. A pesar de ello, la utilidad de este requisito es discutible.

En mi opinión, el requisito de litigio en cortes nacionales es infructífero pues no garantiza la solución definitiva de la controversia. Ello en virtud de que, este tipo de disposiciones constituyen una limitación para la parte que busca acudir a arbitraje, tanto porque se transforma en una posibilidad reducida de solucionar la controversia, cuanto porque las cortes locales no siempre van a emitir una decisión de fondo en un período de tiempo demasiado corto. Así, la controversia va a persistir si el inversionista no se encuentra satisfecho con la decisión de la justicia ordinaria del Estado. Por lo cual, los 18 meses de litigio en cortes locales en diversas ocasiones no solucionan la controversia, más bien la prolongan y causan más costos para el inversionista y para el Estado ${ }^{117}$. En palabras de SCHREUER:

El requisito de intentar un arreglo en los tribunales nacionales del Estado anfitrión durante un cierto período de tiempo parece una reactivación a medias de la regla de

\footnotetext{
115. G. Aravind, Cooling Off Period (Investment Arbitration), MPILux Working Paper 7, 2017, <https://bit.ly/31DeBWc> (15/03/2018).

116. G. Born \& M. ŠCEKIC, "Pre-Arbitration Procedural Requirements: ‘A Dismal Swamp”, en. D. CARON et al., Practising Virtue: Inside International Arbitration, Oxford University Press, 2015, pp. 73.

117. G. Born \& M. Š́́EKIĆ, N. 116, p. 74.
} 
los recursos locales. Pero no parece servir para ningún propósito útil. Los períodos de tiempo previstos para este fin suelen ser demasiado cortos para producir un resultado significativo. Esto es particularmente cierto si los tribunales nacionales del Estado anfitrión son notoriamente lentos. Al final, el inversionista se reserva el derecho de acudir al arbitraje internacional, independientemente del resultado de los procedimientos internos. Desde la perspectiva del inversionista, el intento forzado de buscar justicia a nivel nacional generalmente no será más que un ritual costoso que no tiene otra finalidad que demorar el arbitraje ${ }^{118}$.

Para evadir este requisito, los inversionistas han buscado que se aplique a su controversia una cláusula de resolución de disputas de otro tratado celebrado por el Estado receptor que sea más favorable a través de la cláusula NMF119. Cuando los inversionistas han solicitado importar la cláusula de resolución de disputas de otro tratado mediante la cláusula NMF, los Estados han planteado varios argumentos para que la pretensión del inversionista sea rechazada. Entre ellos, Argentina ha manifestado que los TBIs deberían ser vistos como un "paquete" y que el inversionista solo puede beneficiarse del tratado si acepta todas las condiciones que se han incluido en este ${ }^{120}$.

Asimismo, losEstadoshanargumentadomayoritariamente que la cláusula de NMF no podía extenderse al procedimiento, porque aquello vulneraría el principio ejusdem generis y que el trato de la cláusula NMF se refería únicamente a cuestiones económicas y sustantivas por lo que no podía extenderse a cuestiones de procedimiento ${ }^{121}$.

118. Traducción libre.C. Schreuer, "Calvo's Grandchildren: the return of local remedies in investment arbitration", The Law and Practice of International Courts and Tribunals, Koninklijke Brill NV, 2005.

119. Ídem, p. 75.

120. Instituto Internacional para el Desarrollo Sostenible, The Most-Favoured-Nation Clause in Investment Treaties. IISD Best Practices Series, 2017, <https://bit.ly/2KS2Bcn> (07/03/2018).

121. Emilio Agustín Maffezini c. España, N. 9, párrafos 40-41. 
Otro de los argumentos alegados por los Estados ${ }^{122}$ ha consistido en que el requisito de los 18 meses es una "versión moderada de la regla de agotamiento de recursos internos"123. No obstante, los propios tribunales arbitrales han diferenciado entre el período de litigio en cortes nacionales y el de agotamiento de recursos internos. En tal sentido, los tribunales han afirmado que si se tratara de la condición de agotar recursos internos, el inversionista necesitaría una decisión de los tribunales locales para acudir a arbitraje internacional. En el caso de los 18 meses, el inversionista solo requiere cumplir el tiempo estipulado en el tratado, independientemente de si ha obtenido una decisión judicial o no ${ }^{124}$.

Respecto al consentimiento del Estado para someterse a arbitraje, considero que este no se vería vulnerado por la aplicación de la cláusula NMF debido a que, sin importar si la demanda de arbitraje internacional se presenta en el día uno o en el mes 18, la intención del Estado sigue siendo someter la disputa a arbitraje. Por lo tanto, este período en cortes nacionales no es más que un requisito formal que solo dilata la resolución de la disputa.

Es necesario precisar que pueden existir casos en los que los meses de espera aumenten los daños del inversionista y los gastos en los que deberá incurrir el Estado para repararlos. Ello debido a que, el requisito de litigio en cortes nacionales no supone que se resuelva el conflicto, por el contrario, puede significar tanto para el inversionista como para el Estado un gasto innecesario en relación a una disputa que puede no ser resuelta en cortes nacionales, ya sea porque la neutralidad de las cortes nacionales puede estar en tela de duda o porque la complejidad del caso no permitirá que se llegue a una decisión de fondo en tan poco tiempo.

122. Véase, Siemens A.G. c. Argentina, N. 80.

123. Ídem, párrafo 104.

124. Ibídem. 
Sobre la base de lo expuesto, considero que el requisito sujeto a este análisis solo ocasiona que la reclamación del inversionista se presente casi inmediatamente después de suscitada la controversia, el cumplimiento o la inobservancia de este requisito no altera en absoluto el desarrollo del proceso arbitral ni el consentimiento de las partes para someterse a arbitraje. Por tanto, el requisito de litigio en cortes locales debería ser un requisito alternativo para el inversionista. En palabras de Gary BorN:

[...] tratar los requisitos de litigios locales como presuntamente aspiracionales y exhortatorios, en lugar de presuntamente obligatorios. Solo en casos que involucren un lenguaje claro e inequívoco, un requisito de litigio local debe interpretarse como la imposición de una obligación vinculante y obligatoria $^{125}$.

Aunque son las propias partes quienes deciden cuáles serán los pasos previos al arbitraje, sería errado afirmar que en todos los casos se debe cumplir las etapas previas al arbitraje. En ciertas ocasiones se debe tratar a las cláusulas escalonadas como facultativas. El hecho de no cumplir una etapa previa al arbitraje no siempre va a significar una vulneración al consentimiento de arbitrar de una de las partes. En cada caso habrá que examinar si la omisión de alguno de los requisitos previos al arbitraje por parte del inversionista en realidad modifica el consentimiento del Estado receptor de someterse a arbitraje.

Por lo tanto, el consentimiento de arbitrar no se vería vulnerado de ninguna manera por la desatención a los 18 meses de litigio en cortes nacionales, al final del día, el Estado decidió someterse a arbitraje y si todas las demás condiciones esenciales para que proceda el arbitraje se mantienen intactas, en nada afectaría al Estado que se someta la disputa a arbitraje inmediatamente. Este criterio es compartido por FREYER y Herlihy en los siguientes términos: 
La aplicación de la cláusula NMF en esos casos [Maffezini, Siemens, Camuzzi, Gas Natural] en realidad no modificó el alcance acordado del TBI de la jurisdicción del tribunal ni creó un consentimiento al arbitraje que de otro modo no existía. Afectó meramente el momento del consentimiento del estado receptor al arbitraje del CIADI y permitió que los tribunales escucharan sin demora las demandas sobre las cuales luego tendrían jurisdicción en cualquier caso ${ }^{126}$ (énfasis añadido).

Si bien es cierto que algunos tribunales arbitrales y algunos Estados han sostenido que la razón de ser del tiempo de litigio en cortes nacionales es brindar a los Estados la oportunidad de solucionar la disputa de manera amigable y directa con el inversionista, no podemos dejar de lado el hecho de que el Estado puede cumplir este cometido por medio de negociaciones directas con el inversionista o mediante otros métodos alternativos de solución de disputas. De esta forma, se puede asegurar que realmente las partes no se verán en la necesidad de acudir a arbitraje internacional. También se asegurará que el inversionista estará satisfecho con el acuerdo que haya negociado directamente con el Estado y es poco probable que el inversionista active la vía arbitral.

\subsection{Utilización de la cláusula NMF para que se lleve a cabo el arbitraje bajo un mecanismo de solución de controversias distinto al pactado en el TBI}

Generalmente, los TBIs contienen en sus cláusulas de resolución de disputas disposiciones acerca de la materia que se someterá a arbitraje y el mecanismo de solución de disputas que conducirán el arbitraje entre el inversionista y el Estado. Existen tratados que hacen referencia a un solo sistema de arbitraje, mientras otros le otorgan al inversionista la posibilidad de escoger entre arbitraje CIADI o CNUDMI.

126. Traducción libre. D. H. Freyer \& D. HerLihy, "Most-Favored- Nation Treatment and Dispute Settlement in Investment Arbitration: Just How 'Favored' is "Most Favored", ICSID Review, 2005 , p. 82. 
Los inversionistas han ampliado la aplicación de la cláusula NMF para poder elegir un sistema arbitral que su tratado base no contemplaba. Aquello ha ocurrido en:

El caso Plama c. Bulgaria, el cual envolvía una disputa que se sometió a arbitraje CIADI basándose en los términos del Tratado dela Carta de la Energía y el TBI entre Chipre y Bulgaria. Si bien el TBI Chipre-Bulgaria no previó el arbitraje CIADI, los inversionistas argumentaron que Bulgaria había dado su consentimiento al arbitraje del CIADI en virtud de la cláusula NMF contenida en el tratado. Los reclamantes sostuvieron que la cláusula NMF debe interpretarse como que se extiende a mecanismos de solución de diferencias más favorables que los del TBI Bulgaria-Chipre que están contenidos en otros tratados de inversión celebrados por Bulgaria ${ }^{127}$.

Adiferencia de lo decidido por el tribunal del caso Maffezini, el tribunal del caso Plama c. Bulgaria, negó la petición del inversionista y determinó que al permitir que el inversionista extienda la cláusula NMF a la cláusula de resolución de disputas, se estaría produciendo como efecto pick and choose, es decir, el inversionista podría elegir las disposiciones que los tratados que más le favorezcan, lo cual produciría que los Estados receptores de una inversión se enfrenten a cláusulas de resolución de disputas transformadas ${ }^{128}$. En palabras del tribunal:

Por lo tanto, una referencia puede, en sí misma, no ser suficiente; se requiere que la referencia sea tal que la cláusula de arbitraje sea parte del contrato (es decir, en este caso, el TBI Bulgaria-Chipre). Esta es otra forma de decir que la referencia debe ser tal que la intención de las partes de importar la disposición de arbitraje del otro acuerdo sea clara e inequívoca. No puede decirse que una cláusula que diga "un tratamiento que no sea menos favorable que la otorgada a las inversiones de inversionista es de terceros estados"

127. Plama Consortium Limited c. Bulgaria, N. 20, párrafo 186.

128. Ídem, párrafo 223. 
en el Artículo 3 (1) del TBI entre Bulgaria y Chipre sea una incorporación típica mediante una cláusula de referencia en contratos ordinarios. Genera dudas sobre si la referencia al otro documento (en este caso, los otros TBI concluidos por Bulgaria) incluye clara e inequívocamente una referencia a las disposiciones sobre solución de controversias contenidas en esos TBI ${ }^{129}$.

En el caso Wintershall c. Argentina, el inversionista buscaba que se aplique el artículo VII del TBI Argentina-Estados Unidos, debido a que el TBI Argentina-Alemania establecía que el CIADI era el único y definitivo foro de arbitraje, en tanto que el Artículo VII del TBI Argentina-Estados Unidos, invocado por la actora (en lugar del Artículo 10 del TBI Argentina-Alemania) que disponía que: "un sistema diferente de arbitraje"; otorga a la Demandante (por ejemplo, a un inversionista estadounidense en Argentina) la opción de foros, a saber: el CIADI o la CNUDMI ${ }^{130}$. No obstante, el tribunal arbitral determinó que el artículo 10 del TBI ArgentinaAlemania reflejaba que la intención expresa de los Estados contratantes era someterse a arbitraje ante el CIADI como único y definitivo foro. El tribunal también manifestó que el TBI Argentina-Estados Unidos tenía un mecanismo diferente de arbitraje. Respecto a la cláusula de resolución de disputas, el tribunal arbitral señaló lo siguiente:

[...] la Demandante no puede valerse de la cláusula de la NMF contenida en el Artículo 3 (aun asumiendo que fuera a interpretarse que se extiende al Artículo 10), puesto que lo que la Demandante quiere invocar en su Solicitud de es un sistema distinto de arbitraje conforme a un TBI diferente. Los sistemas de arbitraje de dos tratados nunca pueden ser iguales cuando, en virtud de un tratado, la diferencia ha de resolverse en última instancia únicamente por el arbitraje del CIADI (cuando ambos Estados Contratantes son partes en el Convenio del CIADI), y en virtud del otro tratado (el TBI Argentina-Estados Unidos), la diferencia ha de resolverse, a

129. Traducción libre. Ídem, párrafo 200.

130. Wintershall Aktiengesellschaft c. Argentina, N. 4, párrafo 74. 
opción del inversionista, ya sea por el arbitraje del CIADI o por el arbitraje de la CNUDMI: este último es sin lugar a dudas "un sistema diferente de arbitraje"131.

El tribunal arbitral del caso Garanti Koza c. Turkmenistán conoció la solicitud del inversionista para que se aplique a la controversia la cláusula de resolución de disputas del TBI Turkmenistán- Suiza, según el cual, el inversionista una vez que hubiere agotado los 6 meses de negociaciones directas podía elegir someterse a arbitraje CIADI o arbitraje CNUMDI'132. Empero, el inversionista basaba su reclamación entre el TBI Turkmenistán-Reino Unido que restringía el arbitraje a las reglas CNUDMI. Al resolver, el tribunal afirmó:

El Tribunal considera que la situación del presente caso se asemeja más al caso Plama c. Bulgaria, en el que el Demandante había argumentado que la cláusula de la NMF del Artículo 3 de ese APPRI debía de interpretarse de forma que permitiese que el Demandante primero evitara dos pasos preliminares acordados para la resolución de controversias, para luego reemplazar el mecanismo arbitral acordado (arbitraje ad hoc bajo las reglas de arbitraje del CNUDMI) mediante un arbitraje ante el CIADI. El Tribunal se negó a permitir el uso de la cláusula de la NMF para importar un mecanismo de resolución de controversias completamente nuevo en lugar de un "tribunal de arbitraje internacional 'ad hoc'". Al hacer esto, podría decirse que el tribunal del caso Plama en realidad tomó en cuenta las advertencias contenidas en párrafo 63 del laudo en Maffezini ${ }^{133}$.

Todos los casos nombrados tienen como elemento en común una cláusula de resolución de disputas que prevé un solo mecanismo de arbitraje y un tratado "más favorable" que le da al inversionista la opción de elegir entre un arbitraje bajo reglas CNUDMI o un arbitraje CIADI. Cuando el Estado consiente someterse a arbitraje CIADI o arbitraje bajo reglas

131. Ídem, párrafo 176.

132. Garanti Koza LLP c. Turkmenistán, N. 22, párrafo 76.

133. Tza Yap Schum c. Perú, N. 31, párrafo 220. 
CNUDMI, el consentimiento solo se cumple si se han llevado a cabo todas las condiciones pactadas en el TBI ${ }^{134}$.

En el caso Venezuela US c. Venezuela, el artículo 8(4) del TBI Venezuela- Barbados disponía que cada parte contratante brindaba su consentimiento incondicional para el sometimiento a arbitraje. Según el tribunal, Venezuela había dado un solo consentimiento al arbitraje internacional, no un consentimiento para el CIADI, otro para el mecanismo complementario para el CIADI y, un tercero para el arbitraje CNUDMI. Por lo tanto, el retiro de Venezuela del CIADI significaba que los inversionistas barbadenses no podían iniciar procedimientos arbitrales ante el CIADI. No obstante, el consentimiento de Venezuela de someterse a arbitraje no ha sido retirado ${ }^{135}$. Aplicando la cláusula NMF, el tribunal sostuvo que si en un TBI suscrito entre Venezuela y un tercer Estado hay una condición temporal para el arbitraje bajo el reglamento CNUDMI que sea menos estricta, se podían aplicar las condiciones más favorables. Así, el tribunal se basó en el TBI Venezuela- Ecuador, que contenía una cláusula de resolución de disputas casi idéntica al TBI Venezuela-Barbados y concluyó:

(i) El TBI preveía el recurso de arbitraje CIADI aun cuando solo Ecuador era parte del CIADI.

(ii) El TBIEcuador-Venezuela disponía que hasta que cada Parte contratante del tratado se adhiera al CIADI, la controversia debía resolverse bajo el Reglamento Complementario del CIADI.

El segundo inciso del artículo IX otorgaba al inversionista el derecho de someter una controversia a un tribunal ad hoc en virtud del Reglamento CNUDMI, no sólo cuando por cualquier motivo no estuviere disponible el Mecanismo

134. A. GoEL, Application of MFN clauses to Dispute Settlement Provitions in BITS and its Consequences for Investor State Arbitration, The George Washington University Law School, 2013, p. $19,<$ https://bit.ly/31HY1EH> (15/03/2018).

135. Venezuela US, S.R.L. (Barbados) c. Venezuela, N. 19, párrafo 112. 
Complementario, sino cuando por cualquier motivo no estuviere disponible el propio CIADI. Aquello constituía una diferencia importante en comparación con el TBI BarbadosVenezuela ${ }^{136}$. Finalmente, el tribunal resolvió:

[Venezuela] al haber dado su consentimiento al arbitraje internacional, debe aceptar que los inversionistas de Barbados deban tener acceso al arbitraje CNUDMI, que está enumerado en el Artículo 8(2) del TBI, en condiciones que no sean menos favorables que las condiciones bajo las cuales los inversionistas ecuatorianos tienen tal acceso al arbitraje CNUDMI de conformidad con el Artículo IX del TBI EcuadorVenezuela.

\subsection{Análisis sobre la vulneración al consentimiento del Estado en la modificación del mecanismo de solución de disputas}

A diferencia de lo que ocurre en los casos en los que el inversionista no sigue los requisitos previos al arbitraje, en los que lo único que se altera es el momento en el que se solucionará la disputa, en los supuestos de aplicación de la cláusula NMF para cambiar las reglas del arbitraje, las condiciones que los Estados parte del acuerdo recíproco de protección de inversiones pactaron cambian sustancialmente. Para entender de manera más clara por qué el consentimiento del Estado receptor de una inversión se vería vulnerado por este uso de la cláusula NMF, resulta ineludible analizar las diferencias más importantes de un arbitraje CIADI o de un arbitraje bajo reglas CNUDMI.

En primer lugar, el Convenio CIADI establece que los árbitros no podrán ser de la nacionalidad de ninguno de los Estados parte del $\mathrm{TBI}^{137}$. Este requisito no se encuentra contemplado en el reglamento de arbitraje CNUDMI.

136. Ibídem.

137. Convenio sobre Arreglo de Diferencias Relativas a Inversiones entre Estados y Nacionales de otros Estados (CIADI) (1965), Art. 39. 
Adicionalmente, el Convenio CIADI impone un test de nacionalidad para determinar la jurisdicción del centro ${ }^{138}$, test que no se encuentra previsto en el sistema CNUDMI.

En segundo lugar, según el Convenio CIADI el tribunal arbitral debe decidir la disputa de conformidad con las normas de derecho que hayan sido estipuladas por las partes. A falta de acuerdo, el tribunal decidirá con base en la legislación del Estado parte de la controversia, de acuerdo con las normas de Derecho Internacional Privado o de Derecho Internacional Público que sean pertinentes ${ }^{139}$. Bajo las reglas CNUDMI el tribunal arbitral deberá resolver la controversia aplicando las normas de derecho aplicables al fondo del litigio, si las partes no han acordado una ley aplicable, el tribunal puede aplicar la ley que estime adecuada ${ }^{140}$.

En tercer lugar, el Convenio CIADI otorga a los árbitros la facultad de solicitar a las partes medios de prueba o a su vez, podrá trasladarse al lugar en el que se originó la diferencia y practicar las diligencias de prueba que resulten necesarias ${ }^{141}$. El reglamento CNUDMI también faculta a los árbitros a pedir pruebas y documentos a las partes ${ }^{142}$. Sin embargo, no se menciona si quiera la posibilidad de que los árbitros se trasladen de un lugar a otro para realizar diligencias probatorias.

En cuarto lugar, las consecuencias sobre rebeldía son distintas en el Convenio CIADI y en las reglas CNUDMI. El Convenio CIADI permite a los árbitros conceder un período de gracia ${ }^{143}$ a la parte que no compareció al proceso o que no ejerció sus derechos ${ }^{144}$. Bajo las reglas CNUDMI, cuando una

138. Ibídem.

139. Ídem, Art. 42.

140. Reglamento de Arbitraje de la Comisión de las Naciones Unidas para el Derecho Mercantil Internacional (CNUMDI) (2010), Art. 35.

141. Convenio CIADI, N. 137, Art. 43.

142. Reglamento de Arbitraje de la CNUMDI, N. 140, Art. 27.

143. El período de gracia no procede cuando el tribunal esté convencido de que la parte no intenciones de hacerlo.

144. Convenio CIADI, N. 137, Art. 45. 
parte que haya sido debidamente convocada no comparece y no ejerce sus derechos dentro de los plazos previstos, el tribunal arbitral puede dictar el laudo sobre la base de las pruebas con las que disponga ${ }^{145}$.

En quinto lugar, el Convenio CIADI permite que una de las partes solicite la revisión ${ }^{146}$ del laudo dentro de los 90 días desde el descubrimiento del hecho o hasta 3 años después de la fecha en la que se dictó el laudo ${ }^{147}$. El reglamento CNUDMI no incluye la posibilidad de revisión del laudo.

En sexto lugar, el Convenio CIADI y las reglas CNUDMI establecen un mecanismo diferente para calcular y determinar qué parte debe hacerse cargo de las costas del proceso. En tal sentido, el Convenio CIADI dispone que los gastos del arbitraje serán distribuidos por el tribunal arbitral y formará parte del laudo ${ }^{148}$.

En séptimo lugar, respecto al lugar en que se llevará a cabo el arbitraje, el CIADI dispone que será la sede del Centro y permite que por el acuerdo de las partes se lleve a cabo en las instalaciones de la Corte Permanente de Arbitraje o en otro lugar si se cuenta con la aprobación del tribunal o comisión, previa consulta con el Secretario General. El reglamento de arbitraje CNUDMI no contiene una indicación del lugar del arbitraje, sino que el lugar debe ser pactado por las partes y en ausencia de tal acuerdo será el tribunal quien señale el lugar del arbitraje ${ }^{149}$.

En octavo lugar, otra distinción relevante entre el CIADI y las reglas CNUDMI son los casos en los que procede la anulación del laudo. El artículo 43 de la Ley Modelo CNUDMI establece que sólo se puede anular el laudo en los siguientes casos:

145. Reglamento de Arbitraje de la CNUMDI, N. 140, Art. 30.

146. Para que se realice la revisión quien lo solicite debe basarse en el descubrimiento de algún hecho que pueda influir decisivamente en el laudo cuando el tribunal no haya tenido conocimiento de este hecho y, el desconocimiento no puede ser atribuible a su negligencia.

147. Convenio CIADI, N. 137, Art. 51.

148. Ídem, Art. 62.

149. Reglamento de Arbitraje de la CNUMDI, N. 140, Art. 18. 
a) La parte que interpone la petición pruebe:

i. que una de las partes en el acuerdo de arbitraje a que se refiere el artículo 7 estaba afectada por alguna incapacidad, o que dicho acuerdo no es válido en virtud de la ley a que las partes lo han sometido, o si nada se hubiera indicado a este respecto, en virtud de la ley de este Estado; o

ii. que no ha sido debidamente notificada de la designación de un árbitro o de las actuaciones arbitrales o no ha podido, por cualquier otra razón, hacer valer sus derechos; o

iii. que el laudo se refiere a una controversia no prevista en el acuerdo de arbitraje o contiene decisiones que exceden los términos del acuerdo de arbitraje; no obstante, si las disposiciones del laudo que se refieren a las cuestiones sometidas al arbitraje pueden separarse de las que no lo están, sólo se podrán anular estas últimas; o

iv. que la composición del tribunal arbitral o el procedimiento arbitral no se han ajustado al acuerdo entre las partes, salvo que dicho acuerdo estuviera en conflicto con una disposición de esta Ley de la que las partes no pudieran apartarse o, a falta de dicho acuerdo, que no se han ajustado a esta Ley; o

b) El tribunal compruebe:

i. que, según la ley de este Estado, el objeto de la controversia no es susceptible de arbitraje; o

ii. que el laudo es contrario al orden público de este Estado.

Por su parte, bajo el Convenio CIADI el laudo puede ser anulado cuando se haya incurrido en cualquiera de las siguientes causales ${ }^{150}$.

150. Convenio CIADI, N. 137, Art. 52. 
(a) que el Tribunal se hubiere constituido incorrectamente;

(b) que el Tribunal se hubiere extralimitado manifiestamente en sus facultades;

(c) que hubiere habido corrupción de algún miembro del Tribunal;

(d) que hubiere quebrantamiento grave de una norma de procedimiento; $\mathrm{o}$

(e) que no se hubieren expresado en el laudo los motivos en que se funde.

La diferencia más importante y significativa entre el CIADI y las reglas CNUDMI es el procedimiento de anulación del laudo. El Convenio CIADI prescribe que para la anulación del laudo se debe conformar una comisión ad hoc integrada por tres personas de la lista de árbitros ${ }^{151}$. La comisión puede suspender la ejecución del laudo y en caso de que el laudo sea anulado, la disputa será sometida a un nuevo tribunal arbitral $^{152}$.

Las reglas CNUDMI por el contrario, sugieren que el recurso de anulación se deberá realizar de conformidad con las causales y el procedimiento del Estado sede del arbitraje ${ }^{153}$. A manera ejemplificativa, resulta conveniente mencionar algunos casos en los que se ha discutido la extensión de la cláusula NMF a cuestiones procedimentales y, en los que se ha intentado anular el laudo y, los resultados que se obtuvieron en cada anulación.

Los casos Suez Vivendi c. Argentina, Impregilo c. Argentina y Daimler c. Argentina se llevaron a cabo en el CIADI y su anulación se propuso de acuerdo a las causales previstas en el Convenio CIADI, los resultados fueron los siguientes:

151. Los miembros de la comisión de anulación no pueden haber sido parte del tribunal que decidió la disputa y tampoco pueden tener nacionalidad de ninguna de los Estados parte de la controversia.

152. Convenio CIADI, N. 137, Art. 52.

153. Ley Modelo de la Comisión de las Naciones Unidas para el Derecho Mercantil Internacional (1985), Art. 34. 
El comité de anulación del caso Suez Vivendi manifestó:

En relación con la presunta extralimitación de facultades, el Tribunal no desestimó simplemente la condición del consentimiento establecida en el Artículo X (3) del TBI Argentina-España, como parece sugerir la Demandada, sino que proporcionó razones detalladas sobre por qué consideró que AGBAR podía invocar la cláusula NMF para sortear dicha condición. En este sentido, el Comité coincide con el comité de Impregilo c. Argentina, que determinó que, puesto que la aplicación de una cláusula NMF a disposiciones de resolución de controversias es una cuestión compleja y controvertida, "[n]i la aplicación de la CNMF a cuestiones jurisdiccionales, ni la negativa a aplicarla para arrogarse competencia pueden ser consideradas, por sí mismas, una extralimitación manifiesta de facultades". Según lo establecido además por el comité de Impregilo, no corresponde al Comité, en virtud del Artículo 52 del Convenio del CIADI, hacer un análisis nuevo y detallado de los argumentos presentados por las Partes en la etapa jurisdiccional. El comité de Daimler c. Argentina declaró que "cuando es posible más de una interpretación, el laudo no puede ser anulado sobre la base de que hubo una extralimitación de facultades, mucho menos una extralimitación manifiesta de facultades". El Comité coincide con dicha declaración, excepto quizás en circunstancias extremas, de las que no hay indicio en este caso $^{154}$.

En el caso Daimler c. Argentina el Comité de Anulación resolvió que el tribunal arbitral que resolvió la disputa decidió que los Estados soberanos son libres de consensuar las disposiciones de tratados que elijan con la condición de que estas disposiciones no sean inútiles, por lo cual, el comité determinó que no se habían tomado decisiones contradictorias respecto a la aplicación $\mathrm{NMF}^{155}$.

En el caso Impregilo c. Argentina, el Comité de anulación decidió:

154. Suez et al. c. Argentina, N. 16, párrafo 233.

155. Daimler Financial Services AG c. Argentina, N. 6, párrafo 129. 
[...] el tema de si la CNMF en el TBI Argentina-Italia tiene efectos jurisdiccionales en las circunstancias de este caso que le permitieron a Impregilo acudir al TBI ArgentinaEEUU., que no le exige el recurso a los tribunales locales antes de acudir a la jurisdicción del CIADI, es una cuestión compleja, objeto de debate, con opiniones opuestas que fueron discutidas por la mayoría y el árbitro disidente. $\mathrm{Ni}$ la aplicación de la CNMF a cuestiones jurisdiccionales, ni la negativa a aplicarla para arrogarse competencia pueden ser consideradas, por sí mismas, una extralimitación manifiesta de facultades. Se le solicita al Comité que analice en detalle y de Novo las cuestiones complejas concernientes al debate sobre la jurisdicción en este caso con el fin de respaldar el análisis del árbitro disidente, que considere que dicho análisis debe prevalecer y que concluya que la mayoría se extralimitó manifiestamente en sus facultades. Esta no es la tarea del Comité. El análisis que se requiere para arribar a una conclusión distinta a la de la mayoría implicaría un nuevo y complejo análisis de las cuestiones del caso, análisis que excede la responsabilidad de este Comité en virtud del artículo $52^{156}$.

Uno de los casos que se llevó a cabo bajo las reglas CNUDMI y en el que se pidió la nulidad del laudo arbitral emitido por la Corte Permanente de Arbitraje fue el caso Sanum c. Laos. La acción de nulidad se presentó ante la Corte de Apelaciones de Singapur, la cual aceptó y declaró la nulidad del laudo por la aplicación de la cláusula NMF en los siguientes términos:

Sanum sostiene que si la presentación del Gobierno de Laos es correcta y si un inversionista debe acudir primero a un tribunal nacional competente para determinar si se ha producido una expropiación inadmisible (sobre la base de la interpretación restrictiva del Art. 8 (3)), lo haría Es muy probable que se sienta premeditado luego de someter cualquier disputa, sobre el monto de la indemnización que reclama, a un arbitraje, ya que el tribunal nacional ya habría determinado la cuestión de la compensación. Esto haría que el Art. 8 (3) sea completamente ineficaz ya que, en términos 
prácticos, los inversionistas nunca podrían traer una disputa para el arbitraje inversionista-estado bajo el TBI PRC-Laos. Esta fue la misma opinión adoptada por el Tribunal (en [333] del Laudo), que encontró que la Interpretación Estrecha ofendería el principio de effect utile (que es el principio de interpretación efectiva). Esto requiere que los acuerdos internacionales se interpreten "para darles su peso y efecto más completos en consonancia con el sentido normal de las palabras y con otras partes del texto y de tal manera que se pueda atribuir una razón y un significado a cada parte del texto "(véase la Interpretación del Tratado en la página 1). Hay otras variantes en el mismo punto. ¿Qué pasaría si Sanum (o cualquier otro inversionista) objetara la supuesta expropiación por una variedad de motivos que van desde la falta de interés público, la presencia de discriminación y la cantidad de compensación ofrecida? La perspectiva de tratar de ubicar la disputa en el foro apropiado sin perder el derecho al arbitraje parecería increíblemente difícil ${ }^{157}$.

Como se puede notar, existen diferencias incuestionables entre el Convenio CIADI y las reglas CNUDMI. Esa es la razón por la cual los Estados parte de un tratado, al negociar y pactar una cláusula de solución de disputas, han elegido cuidadosamente el sistema bajo el cual tienen la intención de que se desarrolle el arbitraje. Los inversionistas al invocar la cláusula NMF para acceder a otras reglas arbitrales están alterando el consentimiento del Estado de someterse a arbitraje al cambiar las condiciones del arbitraje y obviar los elementos, especificaciones y ventajas que cada sistema puede ofrecer.

Para concluir, es menester recalcar que en los casos en los que se ha planteado la posibilidad de extender la cláusula NMF a la cláusula de resolución de disputas, la jurisprudencia ha sido contradictoria. Existen casos en los que los tribunales arbitrales han interpretado el silencio acerca del alcance de la cláusula NMF como una aceptación por parte del Estado receptor de la inversión para que el inversionista se beneficie 
de la cláusula de resolución de disputas de otro tratado ${ }^{158}$. Por otra parte, existe otra tendencia en las que los tribunales arbitrales que han interpretado la voluntad de los Estados parte del tratado y sobre la base de las reglas de solución de controversias en el Derecho Internacional Público, han llegado a la conclusión de que las cláusulas NMF no deberían funcionar para obviar una disposición clara y delimitada de una cláusula de solución de disputas que ha sido pactada por dos Estados ${ }^{159}$. En palabras de PARKER:

[...] después de diez años después de la decisión de Maffezini, es seguro decir que ya no existe una "amenaza" de incertidumbre, sino que incertidumbre ya existe. De hecho, incluso Estados que piensan que se han protegido de la “invasión" de la cláusula NMF pueden estar equivocados ${ }^{160}$.

Por lo expuesto, mal se podría afirmar de manera general que la aplicación de la cláusula NMF a cuestiones procedimentales viola el consentimiento del Estado receptor de una inversión de someterse a arbitraje en todos o en ningún caso. De hecho, se debería realizar un análisis de acuerdo a las circunstancias de cada caso y de conformidad con la redacción de cada TBI.

En esta sección se han examinado casos en los cuales los inversionistas han omitido el cumplimiento de etapas previas al arbitraje, específicamente el requisito de litigar 18 meses en cortes nacionales. Como se ha mencionado en esta sección, la aplicación de la cláusula NMF para obviar este requisito no implica una vulneración del consentimiento del Estado para someterse a arbitraje, debido a que este requisito únicamente trae como consecuencia que el inversionista active la vía arbitral inmediatamente después

158. A. Goel, N. 134, p. 57.

159. Ídem, p. 557.

160. Traducción libre. S. L. Parker, A BIT at a Time: The Proper Extension of the MFN Clause to Dispute Settlement Provisions in Bilateral Investment Treaties, American University Washington College of Law: Arbitration Brief, Vol 2, p. 57. 
de que se haya originado la controversia. Al mantenerse incólumes todas las demás condiciones para el arbitraje, el consentimiento para arbitrar no se vería afectado. Es diferente el caso en el que los inversionistas han querido beneficiarse de la cláusula NMF para que el arbitraje se lleve a cabo bajo mecanismos de solución de controversias distintos, ya que como se explicó, existen diferentes sustanciales entre un arbitraje bajo el CIADI y un arbitraje bajo reglas CNUDMI.

En la siguiente sección se examinarán casos en los que los inversionistas han solicitado a los tribunales la aplicación de la cláusula NMF para poder someter a arbitraje protecciones sustantivas que se encontraban excluidas de la cláusula de resolución de disputas del TBI en el que el inversionista basó su reclamación y, casos en los que los inversionistas buscaban aplicar otra definición de inversión mediante la cláusula NMF. Como se demostrará estos usos de la cláusula NMF violan el consentimiento del Estado de someterse a arbitraje en la medida en que se estaría ampliando la jurisdicción del tribunal arbitral, mediante la selección de elementos más favorables de otras cláusulas de solución de disputas.

\section{Uso DE LA CLÁUSUla NMF PARA EXPANDIR LA JURISDICCIÓN DEL TRIBUNAL ARBITRAL EN CUESTIONES SUSTANTIVAS}

A lo largo de este capítulo se detallarán casos en los que los inversionistas han pretendido que se aplique la cláusula NMF para someter a arbitraje protecciones que no estaban previstas en la cláusula de resolución de disputas del tratado base [5.1]. Además, se analizará si este uso de la cláusula NMF modifica o no el consentimiento del Estado para someterse a arbitraje [5.2]. 


\subsection{Utilización de la cláusula NMF para arbitrar cuestiones no contenidas en la cláusula de resolución de disputas}

Existen TBIs que permiten el arbitraje internacional únicamente respecto a una protección específica, ya sea respecto a la expropiación, al monto de compensación por expropiación, a trato justo y equitativo, entre otros. Los inversionistas han hecho uso de la cláusula NMF para expandir la jurisdicción de los tribunales y arbitrar protecciones que se entiende estaban manifiestamente excluidas de la cláusula de resolución de disputas del tratado base. En los casos que se detallarán a continuación, los inversionistas han pretendido, sin ningún éxito, aplicar la cláusula NMF con el propósito mencionado:

En el caso Salini c. Jordania, el demandante presentó su reclamación sobre la base del TBI Jordania-Italia, pero el inversionista buscaba a su vez que el tribunal arbitral se pronuncie sobre el contrato celebrado entre el inversionista con el Estado. El tribunal afirmó que, a diferencia de otros tratados, la redacción del artículo 3 del TBI- Italia-Jordania, no incluía la terminología "all rights or all matters covered by the agreement". Al contrario, según el tribunal la intención de las partes era excluir de la jurisdicción del CIADI cualquier disputa de carácter contractual entre el inversionista y el Estado. Por esas razones, el tribunal concluyó que la disputa debía ser resuelta por el mecanismo de solución de disputas previsto en el contrato de inversión ${ }^{161}$.

En el caso Telenor c. Hungría, el inversionista presentó su reclamación sobre la base del TBI Hungría-Noruega, el cual permitía que se lleve a arbitraje únicamente las disputas relacionadas con expropiación. El inversionista invocó la cláusula NMF para que se aplique a su arbitraje la cláusula de resolución de disputas de otros TBIs que permitían arbitrar

161. Salini Costruttori S.p.A. y Italstrade S.p.A. c. Jordania, N. 23, párrafo 119. 
las controversias relacionadas con el trato justo y equitativo. Al respecto, el tribunal arbitral aseveró que existían cuatro razones por las cuales, el uso de la cláusula NMF no debía extender la jurisdicción del tribunal a categorías de disputas no establecidas en TBI:

(i) En primer lugar, el artículo 31 de la Convención de Viena prescribía que la interpretación de los tratados debía realizarse de buena fe, en concordancia con el uso ordinario de los términos del tratado y de acuerdo al contexto, el objeto y los propósitos del tratado. El tribunal sostuvo que una cosa era estipular que un inversionista podía beneficiarse del tratamiento de nación más favorecida, otra cosa era utilizar la cláusula NMF para traspasar una limitación contenida en el propio TBI, cuando las partes no habían demostrado ni siquiera mediante la redacción que su intención era extender la aplicación de la cláusula NMFi62.

(ii) En segundo lugar, refiriéndose al caso Plama c. Bulgaria, el tribunal decidió que el efecto de darle una interpretación amplia a la cláusula NMF exponía a los Estados a treaty shopping debido a que existían numerosos tratados, con diversas cláusulas de resolución de disputas, algunas de ellas lo suficientemente amplias como para cobijar disputas que en principio, no estarían contenidas en la cláusula de resolución de disputas ${ }^{163}$.

(iii) En tercer lugar, la interpretación amplia de las cláusulas NMF generaban incertidumbre e inestabilidad, ya que una limitación incluida en el tratado podía ser alterada a través de una cláusula de resolución de disputas más extensa de un tercer tratado ${ }^{164}$.

(iv) En cuarto lugar, la interpretación amplia de la cláusula NMF favorecía únicamente al inversionista $\mathrm{y}$, en varias

162. Telenor Mobile Communications A.S. S.p.A. c. Hungría, N. 24, párrafo 92.

163. Telenor Mobile Communications A.S. S.p.A. c. Hungría, N. 24, párrafo 92.

164. Ídem, párrafo 94. 
ocasiones no se realizaba una interpretación conforme a la voluntad de las partes. En los casos en los que los Estados incluían limitaciones al arbitraje en las cláusulas de resolución de disputas, aquellas limitaciones no debían ser transgredidas por un criterio amplio de interpretación.

El tribunal después de analizar otros TBIs celebrados entre Hungría y otros Estados determinó que, de esos 15 tratados, el único tratado que contenía las frases "todas las disputas" o "cualquier disputa" era el TBI celebrado entre Hungría y Noruega. De hecho, los demás tratados suscritos por Noruega contenían especificaciones sobre cuándo una disputa podía ser sometida a arbitraje ante el CIADI. El tribunal determinó que no se podía usar la cláusula NMF para extender la jurisdicción del tribunal, por lo tanto, el inversionista no podía beneficiarse de la cláusula NMF para someter arbitraje disputas que no sean por temas de expropiación.

En el caso Sanumc. Laos, el inversionista solicitó que a través de la aplicación de la cláusula NMF se importe la cláusula de resolución de disputas de los TBIs Laos-Alemania; Laos-Corea o Laos-Reino Unido ${ }^{165}$. El inversionista pretendía ampliar la jurisdicción del tribunal arbitral para que se pronuncie sobre la violación al estándar de seguridad y protecciones plenas ${ }^{166}$. El tribunal arbitral negó la solicitud del inversionista, en los siguientes términos:

La cláusula NMF del Artículo 3(2) se refiere al tratamiento y protección en el Artículo 3(1). El artículo 3(1) establece un trato justo y equitativo y la protección de las inversiones y actividades asociadas con las inversiones de los inversionistas. La Demandante ha argumentado a favor de un sentido amplio del término "protección" en virtud del Artículo 3(1). [...] la posición presentada por la Demandante requiere que el Tribunal: (a) amplíe la "protección" conforme al Artículo 3(1) a todas las protecciones previstas en el Tratado; (b) ampliar el 
alcance del Artículo 3(1) a lo largo del Artículo 3(2); y, (c) ir un paso más allá y extender el alcance de esta cláusula para incluir el acceso al arbitraje con respecto a las disputas sobre el incumplimiento de todas las protecciones bajo el Tratado. El artículo 3 (1) tiene un alcance limitado y no incluye la fórmula tradicional de protección y seguridad plenas, como reconoce la Demandante. Además, leer en esa cláusula una disposición sobre solución de controversia que permita cubrir todas las protecciones en virtud del Tratado cuando el propio Tratado establece un acceso muy limitado al arbitraje internacional, daría lugar a una reescritura sustancial del Tratado y una extensión del consentimiento de los Estados parte al llevar al arbitraje más allá de lo que pueda suponerse que fue su intención, dado el alcance limitado de las cláusulas de protección y solución de controversias del Tratado. Por lo tanto, el Tribunal considera que no tiene jurisdicción para las reclamaciones presentadas de conformidad con el artículo 3 (2) del Tratado (énfasis añadido) ${ }^{167}$.

Algo similar ocurrió en el caso Servier c. Polonia, en el cual, la cláusula de solución de disputas del TBI Polonia-Francia permitía que se sometan a arbitraje internacional únicamente disputas sobre medidas de desinversión. Con el objetivo de expandir la jurisdicción del tribunal, el inversionista invocó la cláusula NMF para que se aplique a su controversia la cláusula de solución de disputas del TBI Polonia-Finlandia, la cual permitía que se someta a arbitraje protecciones como trato justo y equitativo, trato no discriminatorio ni arbitrario, trato nacional y protección y seguridades plenas ${ }^{168}$. El tribunal determinó que las disposiciones de la cláusula NMF del TBI Polonia-Francia no ampliaban la competencia del tribunal arbitral para pronunciarse sobre protecciones que no se traten de desinversiones ${ }^{169}$.

167. Traducción libre. Ídem, párrafos 357-358.

168. El inversionista alegó que las controversias sobre expropiación y compensación por expropiación están relacionadas con el trato justo y equitativo y protección y seguridades plenas. Por lo cual, el tribunal arbitral podía pronunciarse también sobre estas protecciones. Al pronunciarse sobre su jurisdicción, el tribunal arbitral determinó que el hecho de una protección esté relacionada con otra protección del TBI, no puede crear autoridad para que el tribunal se pronuncie sobre temas que no fueron sometidos a arbitraje en el tratado.

169. Les Laboratoires Servier et al. c. Polonia, N. 28, párrafo 511. 
En el caso HH c Egipto, el inversionista pretendía que por la cláusula NMF se aplique la cláusula de resolución de disputas del TBI Egipto-Alemania, en lugar de la cláusula del TBI Egipto-Estados Unidos que era una cláusula fork in the road ${ }^{170}$. El tribunal decidió que la cláusula NMF no podía ser utilizada para evitar la aplicación de la cláusula fork in the road ${ }^{171}$. Adicionalmente, el tribunal arbitral sostuvo que el TBI Egipto-Alemania entró en vigencia después de que el inversionista aceptara la oferta de arbitraje contenida en el TBI Egipto-Estados Unidos ${ }^{172}$.

En el caso Austrian Airlines c. Eslovaquia, el inversionista presentó ante el tribunal arbitral una reclamación por expropiación mediante la aplicación de la cláusula NMF. Sin embargo, la cláusula de resolución de disputas del TBI Eslovaquia- Austria permitía que se someta a arbitraje exclusivamente las disputas sobre el monto de compensación por expropiación. El tribunal analizó los trabajos preparatorios del TBI para conocer la verdadera intención de los Estados contratantes del TBI y determinó que el arbitraje bajo el TBI estaba limitado a la compensación por expropiación. Por lo expuesto, el tribunal consideró que el acceso al arbitraje no estaba comprendido en el ámbito de la cláusula NMF173.

En el caso Berschader c. Federación Rusa, el tratado de inversiones Belga Luxemburgo-Unión Soviética establecía que solo se podían someter a arbitraje internacional las controversias derivadas del monto de compensación por expropiación. A pesar de esto, el inversionista afirmó que se debía aplicar la cláusula NMF para beneficiarse de la cláusula

170. Las cláusulas fork in the road también son conocidas como cláusulas de bifurcación debido a que estas cláusulas permiten al demandante elegir someter una disputa a tribunales nacionales o a un tribunal de inversiones.

171. H\&H Enterprises Investments, Inc c. Egipto, N. 26, párrafo 357.

172. Ídem, párrafo 358.

173. Austrian Airlines c. Eslovaquia, N. 27, párrafos 130-140. 
de solución de controversias del TBI Rusia-Noruega o en caso de duda, la del TBI Rusia-Dinamarca ${ }^{174}$. El tribunal concluyó que la expresión "all matters covered by the present Treaty" no significaba que la cláusula NMF se extendía a todas las protecciones previstas en el tratado. Aquella expresión no demostraba la intención de las partes para que la cláusula NMF se extienda a la cláusula de resolución de disputas. El tribunal finalmente resolvió que el tratado no permitía una incorporación por referencia de la cláusula de resolución de disputas de manera clara e inequívoca ${ }^{175}$.

En el caso Beijing Urban Construction c. Yemen, el demandante pretendió aplicar la cláusula NMF contenida en el TBI Yemen-China para beneficiarse de la cláusula de resolución de disputas del TBI Yemen-Reino Unido, la cual era una cláusula de resolución de disputas más amplia para no verse limitado a solo someter a arbitraje el monto de compensación por expropiación ${ }^{176}$. El tribunal reconoció que aplicar la cláusula NMF a temas procedimentales resultaba un tema controversial y no analizó si se podía o no extender una cláusula de solución de disputas de un TBI a otro, en lugar de hacerlo, el tribunal interpretó la cláusula NFM de acuerdo con los métodos de interpretación del artículo 31 de la Convención de Viena. Así, el tribunal resolvió:

Con respecto a la cláusula NMF, sin embargo, la redacción es diferente. Las palabras "en el territorio" están contenidas en la disposición relativa al "trato otorgado a los inversionistas de la otra Parte Contratante en su territorio con respecto a actividades relacionadas con sus inversiones...". Estas palabras, en opinión del Tribunal, vinculan el NMF a las actividades que tienen lugar "en el territorio" asociadas geográficamente con la inversión. Esta limitación no es coherente con el hecho de que las Partes den su consentimiento al uso del trato NMF para

174. Vladimir Berschader y Moïse Berschader c. Rusia, N. 29, párrafos 85-159.

175. Wintershall Aktiengesellschaft c. Argentina, N. 4, párrafos 194-208.

176. Beijing Urban Construction Group. c. Yemen, N. 33, párrafo 111. 
ampliar el alcance del arbitraje internacional más allá de lo dispuesto en el artículo $10^{177}$.

En el caso Renta 4 c. Rusia, la reclamación del inversionista se basaba en el TBI España-Unión Soviética, el cual permitía someter a arbitraje cuestiones acerca de la compensación por expropiación. Con el propósito de expandir la jurisdicción del tribunal arbitral, el inversionista solicitó que mediante la cláusula NMF se le aplique la cláusula de resolución de disputas del TBI Rusia-Dinamarca por ser más amplia. La pretensión del inversionista fue rechazada por el tribunal, quien al analizar la cláusula NMF estableció:

El demandante, al basarse en una cláusula NMF con respecto a un asunto jurisdiccional, en esencia le pide al tribunal que declare que tiene derecho al "trato" más favorable representado por los términos de un tercer tratado que se ocupa de la jurisdicción del tribunal eso debe ser constituido en caso de una disputa que surja bajo ese tercer tratado. [...] Y aquí se hacen obvios los problemas conceptuales que enfrenta un reclamo de un "trato" más favorable con respecto a la jurisdicción del propio tribunal constituido para resolver el reclamo ${ }^{178}$.

El inversionista en el caso Tza Yap Schumc. Perú presentóuna reclamación referente a expropiación. El inversionista invocó la cláusula 12 del TBI Perú- Colombia, ya que sostuvo que dicho tratado permitía que el inversionista demande ante el CIADI controversias sobre varias protecciones, así, el inversionista sostuvo que mediante la aplicación de la cláusula NMF podía no sólo demandar por temas de expropiación, sino también por violación al trato justo y equitativo. El tribunal consideró que las cláusulas de resolución de disputas y los tratados pueden variar en distinta medida $y$, las palabras "relativa a la compensación por expropiación" o "relativa al monto de la

177. Traducción libre. Ídem, párrafo 120.

178. Traducción libre. Z. DougLAs, The MFN Clause in Investment Arbitration: Treaty Interpretation Off the Rails. Journal of International Dispute Settlement, Vol. 2, No. 1, Oxford University Press, 2011, p. 107. 
compensación por expropiación" se debía interpretar también para cuestiones inherentes a la expropiación, ello en virtud de que se debía determinar si la expropiación se realizó de conformidad con las reglas y requisitos del TBI, así como si el monto por la expropiación era el adecuado ${ }^{179}$.

El tribunal arbitral sostuvo que por naturaleza, el objetivo de una cláusula de NMF era incrementar la protección y otorgar un status más favorable al inversionista. No obstante, el tribunal luego de analizar el artículo 31 de la Convención de Viena y el preámbulo del TBI, confirmó que la intención de las partes consistía en que el alcance de la cláusula NMF debía ser restringido y que no se podía extender la cláusula NMF a la cláusula de resolución de disputas de otro TBI ${ }^{180}$.

Por otra parte, el único caso en el que el inversionista logró que se aplique la cláusula NMF para arbitrar cuestiones no contenidas en la cláusula de solución de disputas del TBI fue en el caso Rosinvest c. Rusia, en el que el inversionista inició una demanda de arbitraje internacional recurriendo a la aplicación de la cláusula NMF del TBI Unión Soviética- Reino Unido para que se aplique la cláusula arbitral del TBI RusiaDinamarca debido a que la cláusula de resolución de disputas del tratado base no permitía al tribunal arbitral decidir sobre la existencia o legalidad de la expropiación ${ }^{181}$.

El tribunal aseveró que si bien es generalmente aceptado que la cláusula NMF se aplicaba a protecciones sustantivas, no había razón para suponer que no se podía aplicar a cláusulas de resolución de disputas ${ }^{182}$. Por esta razón, el tribunal resolvió que la cláusula NMF del TBI Unión Soviética- Reino Unido y la cláusula de resolución de disputas del TBI Rusia-Dinamarca, otorgaban al tribunal arbitral jurisdicción más allá de la

179. Tza Yap Schum c. Perú, N. 31, párrafo 220.

180. Ídem, párrafo 209.

181. RosInvest Co. UK Ltda. c. Rusia, N. 32, párrafo 176.

182. Ídem, párrafo 132. 
prevista en el tratado base y que por lo tanto, la jurisdicción del tribunal se extendía a temas sobre la expropiación y su legalidad ${ }^{183}$.

\subsection{La vulneración al consentimiento a arbitrar del Estado, mediante la aplicación de la cláusula NMF a cuestiones excluidas en el tratado base}

En los casos en los que se ha pretendido utilizar la cláusula NMF para que el tribunal arbitral pueda pronunciarse sobre la legalidad de la expropiación, únicamente el tribunal del caso RosInvest c. Rusia ha aceptado la aplicación de la cláusula NMF para conocer la expropiación y no solo el monto de compensación por expropiación como debió haberlo hecho. Por el contrario, en los casos Renta 4, Beijing Constructions, Berschader, HEH, Austrian Airlines, Salini y Telenor, los tribunales han considerado que la intención de los Estados parte de tratados que limitan al arbitraje al monto de compensación por expropiación ha sido justamente permitir que sus tribunales nacionales sean quienes analicen la legalidad de la expropiación y si ha existido o no vulneración a otras protecciones sustantivas contenidas en el tratado.

Adicionalmente, en los casos Sanum c. Laos y Servier c. Polonia, los inversionistas pretendían que los tribunales arbitrales expandan su jurisdicción a protecciones que no estaban previstas dentro de la cláusula de resolución de disputas del TBI base aplicando la cláusula NMF para arbitrar protecciones que sí podían someterse a arbitraje en cláusulas de solución de controversias de terceros tratados. Afortunadamente, ambos tribunales arbitrales rechazaron los argumentos de los inversionistas y no permitieron que se utilice la cláusula NMF para manufacturar el consentimiento de arbitrar del Estado.

183. Ídem, párrafo 133. 
En esta sección se analizaron casos en los que los inversionistas invocaron la cláusula NMF para expandir la jurisdicción del tribunal arbitral y lograr que se pronuncie sobre violaciones a protecciones no incluidas en la cláusula de solución de controversias. No obstante, los inversionistas también han buscado utilizar la cláusula NMF para importar definiciones de un tratado a otro, esto ocurrió en los casos que se mencionarán a continuación:

En el caso Metal-Tech c. Uzbekistán, el inversionista pretendía que mediante la cláusula NMF contenida en el TBI UzbekistánIsrael se aplique la definición de inversión prevista en el TBI Uzbekistán-Grecia ${ }^{184}$. Sin embargo, el tribunal interpretó las disposiciones del TBI y llegó a la conclusión de que la definición de inversión no tiene vida propia y por tanto, no podía aplicarse la cláusula NMF para beneficiarse de una definición distinta de inversión que la contenida en el tratado base ${ }^{185}$.

Asimismo, en el caso Vanessa Ventures c. Venezuela, el inversionista solicitó al tribunal que aplique la cláusula NMF del tratado TBI Venezuela-Canadá para importar la definición de inversión del TBI Venezuela-Reino Unido ${ }^{186}$. El tribunal resolvió que la cláusula NMF solo podía hacerse valer para proteger las inversiones que se encuentran dentro del ámbito de protección del tratado que las contiene y que no podía ser utilizada para ampliar la categoría de inversiones. ${ }^{187}$

En el caso Rafat Ali Rizvi c. Indonesia, el inversionista buscaba que se aplique la cláusula NMF del TBI IndonesiaReino Unido para beneficiarse de la definición de inversión de los TBIs Indonesia- Holanda, Indonesia- Suiza, IndonesiaOrganización de Cooperación de Estados Islámicos, IndonesiaIndia, Indonesia- Holanda-Bélgica, Indonesia-Alemania,

184. Metal-Tech Ltda. c. Uzbekistán, N. 34, párrafo 132.

185. Ibídem.

186. Vanessa Ventures Ltda. c. Venezuela, N. 35, párrafo131

187. Ídem, párrafo 133. 
Indonesia- Singapur ${ }^{188}$. El tribunal no realizó un análisis sobre la cláusula NMF debido a que consideró que la inversión debía estar protegida por el tratado base y cumplir los requisitos para que califique como tal ${ }^{189}$.

En la mayoría de los casos mencionados, la cláusula de resolución de disputas limitaba el arbitraje a temas relacionados con el monto de indemnización por expropiación o a una protección específica. En mi opinión, la utilización de la cláusula NMF en los casos mencionados en la sección anterior violan el consentimiento del Estado de someterse a arbitraje, debido a que los inversionistas están prácticamente construyendo su propia cláusula arbitral al incluir elementos que se entiende están excluidos del arbitraje.

Es necesario explicar que se podría hacer una distinción entre los casos en los cuales el inversionista pretende que el tribunal amplíe su jurisdicción a una protección no contenida en la cláusula de resolución de disputas del tratado base (ej. trato justo y equitativo) de los casos en que la cláusula de resolución de disputas se limita al arbitraje en temas relacionados con el monto de indemnización por expropiación. En este segundo supuesto, el inversionista buscará que el tribunal se pronuncie primero sobre la existencia y legalidad de la expropiación para luego conocer sobre la adecuada compensación. Se podría argumentar que el tribunal necesariamente deberá examinar en primer lugar la existencia de la expropiación para resolver sobre el monto de compensación adecuado. Si bien este argumento es razonable, en mi opinión se debe respetar la voluntad de los Estados que suscribieron el TBI. Si los Estados decidieron que sus cortes locales serían las únicas competentes para resolver acerca de la expropiación, el tribunal arbitral debería limitarse únicamente a determinar si el monto de la compensación fue el adecuado o no.

188. Vanessa Ventures Ltda. c. Venezuela, N. 35, párrafo 131.

189. Ídem, párrafo 133. 
Respecto a los casos en los que se ha pretendido usar la cláusula NMF para importar la definición de inversión de otro tratado, considero que esta aplicación de la cláusula NMF también atenta contra el consentimiento del Estado para someterse a arbitraje, debido a que un inversionista o una inversión solo pueden beneficiarse de las protecciones de un TBI cuando ostenten la calidad de inversionista o cuando su inversión sea calificada y admitida dentro de la definición de inversión provista por el propio TBI. En consecuencia, cuando los inversionistas buscan que una inversión en principio no estaría protegida por el TBI reciba protecciones mediante la cláusula NMF; no solo se está violentando la voluntad del Estado de arbitrar, sino que se estaría violentando todo el TBI y las disposiciones contenidas en este.

Es primordial tomar en consideración que el arbitraje depende del consentimiento de las partes y está abierto a que los Estados contratantes de un TBI acepten el arbitraje en los términos propuestos ${ }^{190}$. En palabras de Douglas:

La cláusula NMF no incorpora automáticamente los términos de un tercer tratado en el tratado básico. Asegura el trato otorgado por el estado anfitrión a los inversionistas con la nacionalidad requerida en virtud de un tercer tratado en beneficio de los inversionistas con la nacionalidad requerida en virtud del tratado básico. El tratamiento más favorable debe ser identificado y luego comparado con el tratamiento otorgado al reclamante particular. El reclamante debe hacer valer un derecho a un trato más favorable al reclamar a través de la cláusula NMF en el tratado básico. Solo puede hacerlo instituyendo procedimientos de arbitraje y, por lo tanto, aceptando los términos de la oferta permanente de arbitraje en el tratado básico ${ }^{191}$ (énfasis añadido).

Si partimos del supuesto de que el consentimiento al arbitraje es uno de los requisitos primordiales para que se

190. Z. DougLas, N. 178, p. 107.

191. Traducción libre. Ibídem. 
pueda llevar a cabo un arbitraje de inversión ${ }^{192}$, es claro que únicamente en los casos en los que las partes hayan acordado someter una disputa a arbitraje, el árbitro será competente para conocer y resolver aquella disputa ${ }^{193}$. Generalmente, una parte no requiere del consentimiento de la otra para presentar un reclamo en la vía judicial. Sin embargo, si se trata de un caso en el que una parte busca presentar una demanda o una reclamación por la vía arbitral requiere del consentimiento de la otra parte para que esa disputa pueda someterse a arbitraje $\mathrm{e}^{194}$.

Considero que, si el inversionista pretende que mediante la cláusula NMF se pueda ampliar la jurisdicción del tribunal hasta el punto de someter a arbitraje protecciones que no estaban comprendidas en la cláusula de resolución de disputas del TBI, debería al menos existir la intención clara e inequívoca de las partes contratantes del TBI para darle esta aplicación a la cláusula NMF. Este criterio ha sido recogido por el tribunal del caso ICS c. Argentina que ha expresado:

[...] tendría que derivar de la intención clara einequívoca de las Partes Contratantes del TBI y por lo tanto no podría resultar de la incorporación de las disposiciones sobre resolución de diferencias de otros tratados a través de la aplicación de la cláusula de NMF. El hacerlo, de acuerdo a la Demandada, haría que los requisitos contenidos en la disposición sobre resolución de controversias del TBI no tuvieran sentido, ya que cualquier inversionista podría eludirlas ${ }^{195}$.

Los tribunales que han utilizado la cláusula NMF para importar mecanismos de solución de disputas "más favorables", en realidad, están aplicando la cláusula NMF a las condiciones explícitas del consentimiento del Estado ${ }^{196}$. En tal sentido, algunos tribunales arbitrales incluso han llegado

192. I. Ataman-Figanmese, "Manufacturing Consent to Investment Treaty Arbitration by Means of the Notion of 'Arbitration without Privity", Annales, Vol. XLIII, N. 60, 2011, p. 187.

193. Ídem, p. 187.

194. Ídem, p. 188.

195. ICS Inspection and Control Services Limited c. Argentina, N. 5, p. 80.

196. A. Goel, N. 134, p. 19. 
a afirmar que mediante la cláusula NMF se está creando consentimiento donde no existe ${ }^{197}$. Dicha afirmación tiene mucho sentido en los casos en los que los inversionistas han buscado arbitrar cuestiones que no estaban contempladas en la cláusula de solución de disputas del tratado en el que basan su reclamación. No resulta lógico llegar a la conclusión de que si una protección no está comprendida dentro de la cláusula de resolución de disputas del TBI existe consentimiento de arbitrar dicha protección.

Siguiendo esta línea de argumentación, cabe mencionar que las cláusulas de solución de controversias usualmente contienen una disposición clara sobre la materia que se someterá a arbitraje ${ }^{198}$. Además, se debe considerar que la cláusula de resolución de disputas de un TBI debe ser interpretada en su contexto junto con las demás cláusulas del tratado y no aisladamente, por lo cual, resulta lógico concluir que solo se puede someter a arbitraje lo que el tratado indica.

De igual manera, existen tratados que permiten que se someta a arbitraje cualquier controversia que emane de las protecciones otorgadas en el tratado, mientras que otros tratados permiten que se someta a arbitraje las controversias sobre una cuestión en específico o en algunos casos los efectos de la violación a una protección, como ocurre en los TBIs en los que sólo se permite someter a arbitraje las cuestiones relacionadas con el monto de compensación por expropiación.

Cuando un TBI contiene una cláusula de resolución de controversias que hace mención específica a una o varias protecciones del tratado, se debería entender que el silencio respecto de las demás protecciones del TBI no equivale al consentimiento de los Estados de someter a arbitraje

197. Véase, National Grid PLC c. Argentina, N. 11, párrafo 92.

198. I. Welser \& S. Molitoris, "The Scope of Arbitration Clauses or 'All Disputes Arising out of or in Connection with this Contract"”, en C. KLAuSEGger et al. (Eds.), Austrian Yearbook of International Arbitration, MANZ'sche, 2012, p. 18, <https://bit.ly/1RtIWiz> (07/03/2018). 
protecciones no incluidas en la cláusula de resolución de disputas, por tanto, bajo ningún supuesto se podría entender que una protección que no esté contenida en la cláusula de resolución de disputas permite al inversionista invocar la cláusula NMF para que aquella protección sea discutida en sede arbitral. Una interpretación en sentido contrario significaría que el tribunal arbitral está creando mediante la aplicación de la cláusula NMF el consentimiento del Estado de someterse a arbitraje bajo condiciones distintas a las pactadas en el TBI.

Adicionalmente, surge otro problema derivado de la extensión de la cláusula NMF a estos casos, el cual consiste en que el inversionista podría buscar beneficiarse de las disposiciones de la cláusula de resolución de disputas de otro tratado en su totalidad o por el contrario, el inversionista podría elegir cuestiones específicas que le resulten más favorables de varios tratados.

Zachary Douglas sostiene que la dificultad de la extensión de las cláusulas NMF a cuestiones procedimentales está en encontrar un punto medio satisfactorio entre requerir la importación deun tratado completo, por un lado, y permitir que los demandantes seleccionen las disposiciones individuales, o incluso palabras o frases, fuera de contexto ${ }^{199}$. Este criterio ha sido compartido por la profesora Brigitte STERN, quien en su voto disidente del caso Impregilo c. Argentina manifestó:

Los problemas son aún más graves, ya que parece que en la tendencia favorable al uso de la cláusula NMF para ampliar la jurisdicción, la posición no es solo importar del tratado de terceros en el tratado básico la cláusula jurisdiccional en su conjunto, sino importar solo tal o cual aspecto de una cláusula jurisdiccional que parezca más favorable, como se ha hecho en el Laudo mayoritario: en otras palabras, puede haber una política de "escoger y elegir" en la implementación de la cláusula $N M F^{200}$ (énfasis añadido). Concurrente de la profesora Brigitte Stern, 21/06/2011, párrafo, 78. 
Es trascendental recordar que el objetivo esencial de las cláusulas NMF es promover la no discriminación y la armonización. De este modo, las cláusulas NMF promueven una especie de comparación entre TBIs para garantizar que se hagan efectivos los derechos más favorables, incluyendo que existan derechos de procedimiento ${ }^{201}$.

Un asunto fundamental que surge de la aplicación de la cláusula NMF radica en aprobar la modificación unilateral que realizaría el inversionista a la oferta de arbitraje que realizó el Estado receptor de la inversión en el tratado bilateral de inversiones celebrado con el Estado de su nacionalidad, oferta a la que el inversionista se debía limitar a aceptar o rechazar.

Como se mencionó en el primer capítulo, la cláusula de solución de controversias contenida en un TBI consiste en una oferta del Estado para arbitrar, consecuentemente, el inversionista que busca someterse a arbitraje debería hacerlo de acuerdo a lo establecido en la cláusula de resolución de disputas del tratado. Así, si el inversionista intenta cambiar elementos de la oferta que el Estado ha realizado, ya no estaríamos frente a una oferta, sino ante una contraoferta que el inversionista le ha realizado al Estado y, a menos que se pueda determinar que el Estado aceptó dicha contraoferta, el consentimiento para someterse a arbitraje no se ha perfeccionado y por tanto, el arbitraje no podría proceder. En este sentido, FREYER \& HERLIHY afirman:

El consentimiento al arbitraje inversionista / estatal estipulado por los estados contratantes en un tratado de inversión es en realidad una oferta unilateral para arbitrar una clase de disputas potenciales con una clase de demandantes potenciales de acuerdo con las reglas establecidas en el tratado. Cuando un inversionista reclamante inicia un procedimiento de arbitraje contra el Estado Parte contratante anfitrión invocando

201. E. Whiтsiтt, "Application of Most-Favoured- Nation Clauses to the Dispute Settlement Provisions of Bilateral Investment Treaties: An Asseement of the Jurisprudence", Journal of Energy \& Natural Resources Law, Vol. 27, No. 4, 2009, p. 530. 
su consentimiento al arbitraje inversionista/estado en un tratado de inversión, se debe considerar que el inversionista demandante ha aceptado los términos de esa oferta unilateral. En ese momento, cuando el inversionista reclamante inicia un procedimiento de arbitraje, se celebra un acuerdo de arbitraje entre el Estado parte contratante y el inversionista reclamante ${ }^{202}$ (énfasis añadido).

Las tareas con las que se va a enfrentar el tribunal arbitral, no solo consisten en la interpretación de la cláusula NMF, sino en la interpretación de todo el tratado para establecer si las partes están protegidas por el tratado, si la disputa está protegida por el tratado en razón del tiempo y la más importante, que consiste en determinar si el tribunal arbitral tiene jurisdicción respecto a esa disputa específica ${ }^{203}$. En caso de cláusulas NMF amplias ${ }^{204}$ es preciso que el tribunal aplique el principio esjudem generis, con el objetivo de determinar si las disposiciones para resolver las posibles disputas entre el inversionista y el Estado receptor de la inversión pertenecen a la misma categoría a la que se refiere la cláusula $\mathrm{NMF}^{205}$. En este sentido, el tribunal del caso Daimler c. Argentina estableció:

La cuestión no es si permitir que el Demandante importe todas o partes de la cláusula de resolución de disputas inversionista-Estado del TBI del comparador protegería y promovería mejor la inversión, ni si el Demandante preferiría poder hacerlo, sino más bien si Alemania y Argentina, al concluir el TBI, acordó proteger y promover la inversión de esa manera particular. Esta pregunta no puede responderse con referencia a opiniones externas sobre qué tipos de resolución de disputas pueden proteger mejor y promover la inversión en abstracto. Tampoco se puede responder haciendo referencia a la preferencia de un reclamante por más opciones sobre menos opciones. Sólo se puede responder haciendo referencia al alcance del consentimiento de los Estados Parte expresado en el TBI germano-argentino ${ }^{206}$.

202. Traducción libre. D. H. Freyer \& D. Herlihy, N. 126, p. 83.

203. Ibídem.

204. Contienen una lista no exhaustiva sobre en qué consiste el "tratamiento" más favorable.

205. S. L. PARKer, N. 160, p. 49.

206. Traducción libre. Daimler Financial Services AG c. Argentina, N. 6, párrafo 186. 
Por último, cabe mencionar que el consentimiento de un Estado a la jurisdicción de un tribunal arbitral no es una cuestión de grados. El Estado no brinda su consentimiento para someterse a arbitraje fuertemente o débilmente; el consentimiento se manifiesta de forma binaria: existe consentimiento o el consentimiento está ausente ${ }^{207}$. La decisión final siempre estará en manos del tribunal arbitral y es al tribunal a quien le corresponderá determinar si el consentimiento del Estado de someterse a arbitraje bajo condiciones transformadas unilateralmente por los inversionistas en realidad existe, de lo contrario, el tribunal se limitará a fabricar dicho consentimiento.

\section{Conclusiones}

La cláusula NMF ha permitido a los inversionistas extranjeros beneficiarse de un trato no menos favorable que el trato otorgado a inversionistas de nacionalidad de un tercer Estado. Para que opere la cláusula NMF es necesario que exista un tratado base que contenga la cláusula NMF y que, a su vez, exista un tercer tratado que haya sido celebrado entre el Estado receptor de la inversión y cualquier otro Estado.

En principio, es indiscutible que los inversionistas pueden solicitar la aplicación de la cláusula NMF para protecciones sustantivas contenidas en el tercer tratado. No obstante, los inversionistas en numerosas ocasiones han tratado de extender la aplicación de la cláusula NMF a temas procedimentales, en algunos casos alterando el consentimiento del Estado receptor de una inversión de someterse a arbitraje.

A lo largo de este artículo se analizaron casos en los que se invocó la aplicación de la cláusula NMF. Se presentaron casos en los que se pretendía no cumplir el requisito de litigio en cortes nacionales por un período de tiempo determinado, para

207. A. Goel, N. 134, p. 21. 
lo cual se analizaron los casos: Wintershall c. Argentina; ICS c. Argentina; Daimler c. Argentina; Impregilo c. Argentina; Kilic c. Turkmenistán; Maffezini c. España; Gas Natural c. Argentina; National Grid c. Argentina; Hochtief c. Argentina; Camuzzi c. Argentina; AWG c. Argentina; Phillip Morris c. Uruguay; Suez c. Argentina; Telefónica c. Argentina; y Teinver c. Argentina. A pesar de que no en todos los casos los tribunales aceptaron la aplicación de la cláusula NMF para obviar este requisito, se comprobó que el requisito del período de litigio en cortes nacionales no alteraba las condiciones esenciales para que proceda el arbitraje, por lo cual, deben ser considerados requisitos facultativos para las partes debido a que solo dilatan la solución de la controversia.

De igual manera, se analizó si la aplicación de la cláusula NMF para cambiar las reglas bajo las cuales se debía manejar el arbitraje constituía una violación al consentimiento del Estado. Para ello, se examinaron los casos Plama c. Bulgaria, Wintershall c. Argentina, Garanti Koza c. Turkmenistán y Venezuela U.S. c. Venezuela, en los cuales casi todos los tribunales determinaron que no era posible aplicar la cláusula NMF para cambiar el sistema procedimental del arbitraje. De este modo, se logró demostrar que existen diferencias sustanciales entre las disposiciones del Convenio CIADI y las reglas CNUDMI, diferencias que son esenciales para el Estado al momento de negociar y pactar una cláusula resolución de disputas en un TBI.

Finalmente, se estudiaron los casos: Salini c. Jordania; Telenor c. Hungria; Sanum c. Laos; HEH c. Egipto; Austrian Airlines c. Eslovaquia; Berschader c. Rusia; Renta 4 c. Rusia; Tza Yap Schum c. Perú; RosInvest c.Rusia; Beijing Urban Constructions c. Yemen; Servier c. Polonia; Metal-Tech c. Uzbekistán; Vanessa Ventures c. Venezuela; y Rafat Ali Rizvi c. Indonesia, en donde los inversionistas buscaban someter a arbitraje protecciones 
que no estaban contenidas en la cláusula de solución de disputas del TBI o protecciones que no estaban contenidas en el tratado que contenía un "trato más favorable". No obstante, la mayoría de tribunales no permitió esta aplicación de la cláusula NMF. A lo largo del tercer capítulo se comprobó que esta aplicación de la cláusula NMF constituye una violación al consentimiento del Estado de someterse a arbitraje porque si una protección no se encuentra expresamente contemplada en la cláusula de solución de disputas, no se podría interpretar ese silencio como la aceptación de arbitrar cualquier disputa relacionada con cualquier protección.

Por todo lo expuesto, mal se podría afirmar de manera general que la aplicación de la cláusula NMF a cuestiones procedimentales viola el consentimiento del Estado receptor de una inversión de someterse a arbitraje en todos o en ningún caso. De hecho, considero que se debería realizar un análisis de acuerdo a las circunstancias de cada caso y de conformidad con la redacción de cada TBI.

En definitiva, se puede asemejar al arbitraje internacional de inversiones como un destino final al que las partes buscan llegar o al que eventualmente llegarán. Si el destino es el mismo que los Estados parte del TBI negociaron y pactaron, el hecho de que un inversionista tome un atajo para llegar a ese destino más rápido, no afecta las demás condiciones esenciales por el que las partes escogieron el arbitraje y por tanto, el consentimiento del Estado de someterse a arbitraje no se ve vulnerado.

Es distinto, el caso en el que los inversionistas pretenden llevar al Estado a un destino parecido o "más favorable" del que se pactó en un tratado; el destino puede ser parecido e incluso mejor desde la perspectiva del inversionista. Sin embargo, no es el destino al que los Estados acordaron llegar. Consecuentemente, en los casos en los que se pretende arbitrar 
una protección no prevista en la cláusula de resolución de disputas del TBI ocuando se alteran las reglas de procedimiento, el consentimiento del Estado de someterse a arbitraje se vería transgredido. 